IZA DP No. 7805

Fiscal Policy, Sovereign Default, and Bailouts

Falko Juessen

Andreas Schabert

December 2013 


\title{
Fiscal Policy, Sovereign Default, and Bailouts
}

\author{
Falko Juessen \\ University of Wuppertal \\ and IZA
}

Andreas Schabert

University of Cologne

\section{Discussion Paper No. 7805 \\ December 2013}

\author{
IZA \\ P.O. Box 7240 \\ 53072 Bonn \\ Germany \\ Phone: +49-228-3894-0 \\ Fax: +49-228-3894-180 \\ E-mail: iza@iza.org
}

Any opinions expressed here are those of the author(s) and not those of IZA. Research published in this series may include views on policy, but the institute itself takes no institutional policy positions. The IZA research network is committed to the IZA Guiding Principles of Research Integrity.

The Institute for the Study of Labor (IZA) in Bonn is a local and virtual international research center and a place of communication between science, politics and business. IZA is an independent nonprofit organization supported by Deutsche Post Foundation. The center is associated with the University of Bonn and offers a stimulating research environment through its international network, workshops and conferences, data service, project support, research visits and doctoral program. IZA engages in (i) original and internationally competitive research in all fields of labor economics, (ii) development of policy concepts, and (iii) dissemination of research results and concepts to the interested public.

IZA Discussion Papers often represent preliminary work and are circulated to encourage discussion. Citation of such a paper should account for its provisional character. A revised version may be available directly from the author. 
IZA Discussion Paper No. 7805

December 2013

\section{ABSTRACT}

\section{Fiscal Policy, Sovereign Default, and Bailouts}

This paper examines fiscal policy without commitment and the effects of conditional bailout loans. The government relies on distortionary taxation and decides between full debt repayment and costly default. It tends to overborrow due to myopia, which induces default to be a relevant policy option and provides a rationale to constrain sovereign borrowing. We consider a lump-sum financed fund that offers loans at a favorable price and conditional upon minimum primary surpluses. While the government prefers defaulting in the most adverse states, we find that it is willing to accept conditional loans in close-to-default states. These bailouts can lead to an increase in the mean debt price and a lower default probability that are associated with enhanced household welfare. Yet, these outcomes can be reversed when bailouts are too generous, while public debt never decreases in the long-run when bailout loans are available.

JEL Classification: E32, H21, H63

Keywords: discretionary fiscal policy, overborrowing, sovereign default, bailout loans, conditionality

Corresponding author:

Andreas Schabert

University of Cologne

Center for Macroeconomic Research

Albertus-Magnus-Platz

50923 Cologne

Germany

E-mail: schabert@wiso.unikoeln

\footnotetext{
*We are grateful to Klaus Adam, Felix Bierbrauer, Kai Christoffel, Christian Bayer, Hans-Peter Grüner, Christian Hellwig, Michael Krause, Dirk Krüger, Bartosz Mackowiak and Harald Uhlig for helpful comments and suggestions. Financial support of the DFG SPP 1578 is gratefully acknowledged.
} 


\section{Introduction}

In the aftermath of the subprime crisis, several industrialized countries have experienced a substantial worsening of the fiscal stance, i.e. high public deficits and debt-to-GDP ratios. As a consequence, sovereign default risk, which has previously been viewed as particularly relevant for less developed countries and emerging market economies, has become a serious issue for industrialized countries as well. These countries are typically characterized by larger shares of domestically held public debt (see Reinhart and Rogoff, 2011), while expectations of public sector default are mainly based on the reluctance of governments to lower deficits or to generate surpluses. Given that increasing costs of borrowing tend to aggravate this problem, bailout loans have recently been offered to members of the European Monetary Union (EMU) at favorable terms and conditional upon fiscal policy adjustments, similar to the conditionality of past International Monetary Fund (IMF) supported programs. Since Fall 2012, conditional bailout loans are supplied by the European Stability Mechanism (ESM), a financial institution which is funded by the majority of members of the EMU. In this paper, we examine the consequences of this type of bailouts, i.e. self-financed loans at a favorable price and conditional upon fiscal consolidation, focussing on the following questions: $i$.) When will governments accept conditional loans? ii.) How do bailouts affect sovereign borrowing in the long-run and household welfare?

To address these questions, we apply a closed economy model with a government that lacks commitment when raising distortionary taxes, purchasing goods, and borrowing in terms of non-state-contingent debt. To account for debt accumulation, we consider government myopia which induces overborrowing, since lack of commitment alone is known not to be sufficient to explain a positive long-run level of public debt (see Debortoli and Nunes, 2012). The government discretely decides between full debt repayment and costly default on outstanding debt. It thereby faces a trade-off between defaulting, which disburdens the government from raising revenues for debt repayment, and repaying debt to avoid costs of default, which are modelled as deadweight resource losses (like in Cole and Kehoe, 2000, or Arellano, 2008). In contrast to the majority of studies on sovereign default, we do not consider foreign lending, such that gains of default arise here mainly by allowing to reduce distortionary taxes or/and to raise utility providing government consumption. ${ }^{1}$ Facing the trade-off between gains and costs of default, a myopic government is found to default with a non-negligible probability.

\footnotetext{
${ }^{1}$ Most contributions to the sovereign default literature follow Eaton and Gersovitz (1981), where fiscal policy is not explicitly modelled when the government considers defaulting on foreign debt (see e.g. Aguiar and Gopinath, 2006, or Arellano, 2008). Exceptions are Cole and Kehoe (2000) and Cuadra et al. (2010), where fiscal instruments are taken into account for the analysis of sovereign default.
} 
The basic fiscal policy problem without bailout loans can be summarized as follows. The government neither commits itself to a tax/spending plan nor to repay debt. When default costs are prohibitively high, it never opts in favor of default. If the government were not myopic, the time consistent fiscal policy would then be optimal, i.e. it would be identical to the fiscal policy plan under full commitment. ${ }^{2}$ Under non-prohibitive default costs, lack of commitment affects the government's choices. Investors internalize the possibility of default such that the price of government bonds becomes debt elastic. When the state of the economy worsens and public debt increases, the costs of borrowing increase, such that the government mostly relies on raising taxes and/or reducing expenditures to balance the budget. This policy response in fact relates to the austerity measures conducted by the Greece government before it was bailed out in May 2010. ${ }^{3}$ As the government trades off the costs of increasing surpluses and the costs of default, it decides to default when the state of the economy becomes more adverse, i.e. when outstanding debt is high and income is low. Myopia then increases the probability of default and leads to higher welfare losses, providing a rationale for conditional bailout loans. ${ }^{4}$

This framework is used to assess the effects of loans that are offered at a favorable price and conditional upon repayment of previous debt as well as a minimum primary surplus by an institution which is independent of the government and financed by households. ${ }^{5}$ This institution, which we call the fund, cannot enforce the government, implying that the latter must voluntarily comply with the conditionality to be eligible for these loans and that they are also subject to default risk. Nonetheless, the fund can in principle induce beneficial effects on equilibrium outcomes, since we assume that it disposes of superior technologies compared to the government, i.e. it has access to lump-sum financing and is able to commit to a pre-specified policy. The answers to the above-mentioned questions can be summarized as follows:

i.) Conditional loans at favorable prices are attractive for an indebted government when the interest rate charged by domestic households is high. Accordingly, we find that conditional loans are accepted by the government at the boundary between repayment and

\footnotetext{
${ }^{2}$ This equivalence relies on the assumption that the utility function is quasi-linear (as in Cole and Kehoe, 2000), which further facilitates the analysis of discretionary policy, since it implies risk-neutral investors.

${ }^{3}$ See Ardagna and Caselli (2012) for a comprehensive analysis of the recent bailouts of Greece.

${ }^{4}$ Here, optimal policy under commitment is welfare superior, even though default can induce debt to be state contingent. For an analysis of welfare gains from defaulting, see Adam and Grill (2012), who examine sovereign default when the borrower acts under full commitment and show that default can be optimal under disaster-like shocks.

${ }^{5}$ A more realistic specification of the bailout loan should certainly consider a multiperiod fiscal consolidation plan and tranches of financial assistance, which we view as less relevant for the main results of the analysis.
} 
default states, indicating that these loans indeed serve as bailouts for the government in states close to default. The government's willingness to accept conditional loans increases when the fiscal constraint becomes less tight, i.e. when the minimum primary surplus decreases. Nevertheless, the government tends to default in the most adverse states, implying that bailouts do not prevent defaults.

ii.) When conditional loans are accepted by the government, the level of public debt is reduced in the short run and the bond price increases. We find that the probability of bailouts as well as the long-run level of public debt increase with the generosity of conditional loans. When the fiscal constraint is not too tight to be acceptable, bailout loans can lead to a lower default probability and enhanced household welfare. However, these outcomes are reversed when conditional loans are too generous, i.e. when the short-run beneficial effects of bailouts are overturned by the long-run increase in public debt.

The paper builds on the literature on optimal fiscal policy in a closed economy with nonstate-contingent debt (see e.g. Aiyagari et al., 2002) and under lack of commitment (see e.g. Klein et al., 2008, or Debortoli and Nunes 2013). With D'Erasmo and Mendoza (2013), who focus on the effect of sovereign default on the wealth distribution, and Pouzo (2013), who examines optimal taxation with sovereign default, we share the assumption that the public debt on which the sovereign defaults is held by domestic investors. Our specification of the discrete default choice and the resource costs of default relates to several studies on sovereign default in small open economies, like Arellano (2008) or Cuadra et al. (2010). Finally, our bailout analysis relates to Boz (2011), who examines how emerging market sovereign borrowers decide between private loans and loans from international financial institutions, which are characterized by a superior repayment enforcement, and to Roch and Uhlig (2012), who analyze sunspot shocks and discuss the effects of bailout loans that are offered at fundamental prices.

The remainder of the paper is structured as follows. Section 2 presents the model. Section 3 describes the choice of an optimizing government under lack of commitment and its relation to the optimal policy under commitment. In Section 4 we present numerical results for the case without conditional loans and then show how the introduction of conditional loans affect the government's borrowing behavior and household welfare. Section 5 concludes. 


\section{The model}

In this section, we describe a closed economy model with endogenous production. Households consume, supply working time, and invest in non-state-contingent government bonds. The government raises labor income taxes and purchases goods, while it lacks commitment. Debt repayment is modelled as a discrete choice, i.e. public debt is either fully repaid or not at all, where default is assumed to be associated with resource losses, as in Cole and Kehoe (2000) or Arellano (2008). A fund is further assumed to offer loans at a favorable price, conditional upon repayment of outstanding debt and on a minimum value for the current primary surplus.

\subsection{The private sector}

There exists a continuum of infinitely lived and identical households of mass one. Their utility is increasing in consumption $c_{t}$ and government expenditures $g_{t}$, and decreasing in working time $l_{t}$. The objective of a representative household is given by

$$
E \sum_{t=0}^{\infty} \beta^{t} u\left(c_{t}, g_{t}, l_{t}\right), \quad \text { with } \beta \in(0,1),
$$

where $E$ denotes the expectations operator based on information at the beginning of period 0 and $\beta$ denotes the discount factor. The utility function $u$ is twice continuously differentiable in consumption $c_{t}$, government spending $g_{t}$, and working time $l_{t}$, and satisfies $u_{c}>0, u_{c c} \leq 0$, $u_{g}>0, u_{g}<0, u_{l}<0$ and $u_{l l}<0$.

Households can invest in government bonds $b_{t}^{h}$ and borrow/lend by issuing/buying oneperiod non-state-contingent bonds $b_{t}^{r f}$. We assume that households fully commit to repay debt. In period $t$, bonds $b_{t}^{r f}$ are issued at the price $1 / R_{t}^{r f}$ and delivers one unit of the consumption good in period $t+1$, such that $R_{t}^{r f}$ is the risk-free rate. ${ }^{6}$ Government debt is issued at the price $q_{t}=1 / R_{t}$ and pays out one unit of the consumption good in period $t+1$ under full repayment. Yet, the government does not commit to repay and might default on outstanding debt in $t+1$. Labor income is taxed at a rate $\tau_{t} \in(0,1)$. The ex-post budget constraint reads

$$
c_{t}+\left(b_{t}^{h} / R_{t}\right)+\left(b_{t}^{r f} / R_{t}^{r f}\right) \leq\left(1-\tau_{t}\right) w_{t} l_{t}+p_{t} b_{t-1}^{h}+b_{t-1}^{r f}+\Pi_{t}-f_{t}^{b},
$$

where $\Pi_{t}$ denotes firms' profits, $w_{t}$ the wage rate, and $f_{t}^{b} \geq 0$ a lump-sum fee paid to the fund (see Section 2.2). Note that $p_{t}$ indicates whether the government fully repays its outstanding

\footnotetext{
${ }^{6}$ Note that risk-free bonds can also be issued by the fund (see Section 2.2).
} 
debt, $p_{t}=1$, or defaults in period $t, p_{t}=0$. Households rationally take into account the possibility of default, where expectations about the repayment probability $E_{t}\left(1-\delta_{t+1}\right) \geq 0$ depend on the government behavior. Households maximize (1) subject to (2), a no-Ponzi game condition, $\lim _{t \rightarrow \infty}\left(b_{t}^{r f} / R_{t}^{r f}\right) \prod_{i=1}^{t} 1 / R_{i-1}^{r f} \geq 0$, and $b_{t}^{h} \geq 0$. The households' first order conditions are given by

$$
\begin{aligned}
-u_{l}\left(c_{t}, g_{t}, l_{t}\right) & =u_{c}\left(c_{t}, g_{t}, l_{t}\right)\left(1-\tau_{t}\right) w_{t}, \\
u_{c}\left(c_{t}, g_{t}, l_{t}\right) & =R_{t} \beta E_{t}\left[\left(1-\delta_{t+1}\right) u_{c}\left(c_{t+1}, g_{t+1}, l_{t+1}\right)\right], \\
u_{c}\left(c_{t}, g_{t}, l_{t}\right) & =R_{t}^{r f} \beta E_{t} u_{c}\left(c_{t+1}, g_{t+1}, l_{t+1}\right),
\end{aligned}
$$

and the transversality conditions for privately issued bonds, $\lim _{t \rightarrow \infty} E\left(b_{t}^{r f} / R_{t}^{r f}\right) \prod_{i=1}^{t} 1 / R_{i-1}^{r f}=$ 0 , and government bonds, $\lim _{t \rightarrow \infty} E\left(b_{t}^{h} / R_{t}\right) \prod_{i=1}^{t} 1 / R_{i-1}^{r f}=0$.

The final good $y_{t}$ is produced by identical and infinitely many firms of mass one and is purchased by households and the government for consumption only. Firms are perfectly competitive and their production technology is given by

$$
y_{t}=\Xi\left(a_{t}, p_{t}\right) f\left(l_{t}\right)
$$

where $a_{t}$ is a stochastic productivity level satisfying $a_{t} \in \Upsilon$ and $\pi\left(a_{t+1} \mid a_{t}\right)$ are the transition probabilities. The productivity factor $\Xi_{t}$ is weakly increasing in $a_{t}$ and is adversely affected when the government decides to default in period $t, p_{t}=0$. Specifically, we assume that $\Xi\left(a_{i, t}, 0\right) \leq \Xi\left(a_{i, t}, 1\right)$ for any productivity level $a_{i, t} \in \Upsilon$, such that default triggers temporary resource losses, like in Arellano (2008) or Cuadra et al. (2010). The specification of default losses in terms of the productivity factor $\Xi\left(a_{t}, p_{t}\right)$ can be viewed as a short-cut of modelling the adverse effects of sovereign default on the balance sheet of public debt holding banks and on the supply of credit to the private sector, which seems to be the main source of costs that deter sovereign borrowers from defaulting (see, for example, Panizza et al., 2009). Firms maximize profits taking prices as given and subject to (6), such that labor demand satisfies $w_{t}=\Xi\left(a_{t}, p_{t}\right) f^{\prime}\left(l_{t}\right)$.

\subsection{The fund}

We consider an independent institution which supplies loans to the sovereign borrower. This institution is modelled to account for main features of the European Stability Mechanism (ESM). Specifically, we assume that it is organized as a fund that raises revenues by collecting fees and by issuing one-period non-state-contingent bonds. The fund offers loans to the government conditional upon repayment of current outstanding debt and a fiscal constraint. 
In contrast to the government, we assume that the fund has access to lump-sum financing and is able to commit to its future activities. ${ }^{7}$ Due to these superior technologies the fund can induce beneficial effects on equilibrium outcomes and thus on household welfare. Yet, we show that this will not be the case when the offer is too generous. In case the fund is specified in a way that it actually leads to a welfare improvement, the fund can alternatively be interpreted as being voluntarily supported by households. Households could then authorize the fund to raise revenues, for example, in the initial period as seed capital, to finance the loans.

In all periods and states, the fund offers a one-period loan $b_{t}^{b}$ at a favorable price conditional upon repayment of previous debt $\left(p_{t}=1\right)$ and conditional upon a constraint on current fiscal policy choices that is in principle suited to increase the likelihood of repayment and to induce lower future sovereign debt levels. Thereby, the conditional loan can address two main sources of inefficiency: Overborrowing induced by the government's myopia can be restrained by imposing the fiscal constraint and the adverse effect of the lack of commitment on bond prices can be avoided by offering a more favorable price.

We do not examine an optimizing behavior of the fund, which requires being explicit about its objective. While it would be obvious to consider that it should maximize household welfare, the institutions that provide bailout loans (like the IMF or the ESM) rather seem to aim at avoiding sovereign default and at reducing the future level of debt. Instead of deriving an optimal plan of the fund we consider a simple pre-specified policy of the fund, which allows us to disclose parametrically how the terms of the loan affect the government's willingness to accept the fund's offer and its borrowing behavior. In particular, we assume that loans are offered at the risk-free price $1 / R_{t}^{r f}$ and conditional upon not defaulting on previous debt and a current surplus $s_{t}=\tau_{t} a_{t} \alpha l_{t}^{\alpha}-g_{t}$ being sufficiently large relative to the current debt level,

$$
s_{t} \geq \Psi \cdot b_{t} .
$$

The parameter $\Psi>0$ governs the strength of the fiscal constraint and will be varied in the numerical analysis (see Section 4.3) to disclose when the government is actually willing to accept the loan and how the conditionality affects public debt in the long-run and household welfare. The fiscal constraint (7) implies that the government is neither forced to implement a certain amount of expenditures nor does the fund impose a particular level of the tax rate. The government is free to optimally choose its instruments $\left(g_{t}, \tau_{t}\right)$, while satisfying the

\footnotetext{
${ }^{7}$ We disregard the case where the fund can directly transfer resources to the government, which can obviously lead to superior outcomes.
} 
constraint on the current primary surplus (7). It should further be noted that the government does not rely on a (potentially incredible) commitment to future surpluses to be eligible for the fund's loan and that the fund is not endowed with a specific enforcement technology. Hence, repayment of the loan is not guaranteed and depends on the government's decision to repay debt in the subsequent period. The budget constraint of the fund is thus given by

$$
\left(b_{t}^{b} / R_{t}^{r f}\right)-p_{t} b_{t-1}^{b}=\left(b_{t}^{r f} / R_{t}^{r f}\right)-b_{t-1}^{r f}+f_{t}^{b},
$$

where we assumed that it is able to commit to repay its own debt. The fund's loan $\left(1 / R_{t}^{r f}, \Psi\right)$ is in general inconsistent with an individually rational behavior of a price-taking investor. According to the optimal investment choice, households are only willing to offer a loan at the price $1 / R_{t}^{r f}$ if full repayment is guaranteed. In particular, a credit to the government at the risk-free price $1 / R_{t}^{r f}$ is only consistent with individual rationality if the constraint (7) with $\Psi^{*}$ leads to a new debt level $b_{t}^{*}$ that induces the government to voluntarily decide to fully repay debt in the subsequent period in all states. Hence, choosing taxes and government expenditures, $\tau_{t}$ and $g_{t}$, in a way that end-of-period debt equals $b_{t}^{*}$ can already be realized by borrowing from households, implying that offering a loan $\left(1 / R_{t}^{r f}, \Psi^{*}\right)$ would neither affect the government choice nor the equilibrium outcome. To provide a non-trivial analysis, we therefore consider loans with a fiscal constraint (7) that induces a loan size different from (i.e. larger than) $b_{t}^{*}$. Given that these loans turn out to be accepted only in close-to-default states or in states where the government would otherwise default, we will refer to them as bailout loans.

\subsection{The government}

The government purchases the amount $g_{t}$ of the final good, raises labor income taxes, and issues non-state-contingent one-period bonds. We assume that the government cannot credibly commit to its future policy actions. In contrast to Krusell et al. (2006) and Debortoli and Nunes (2013), who also examine fiscal policy when the government cannot commit to a taxation and spending plan, we do not assume that the government can nevertheless commit to repay debt. Instead, we assume that the government does not guarantee debt repayment and consider the default decision as a discrete choice, like in the literature on sovereign default (see Eaton and Gersovitz, 1981, or Arellano, 2008). The government thus acts on a period by period basis by choosing the amount of goods purchases, the tax rate, and whether to fully repay debt or not. It thereby treats loans from households and from the fund in an identical way. We assume that in each period the government aims at maximizing the sum 
of discounted household utility over an infinite horizon

$$
V_{t}=\max E_{t} \sum_{k=0}^{\infty} \widetilde{\beta}^{k} u\left(c_{t+k}, g_{t+k}, l_{t+k}\right),
$$

while its particular objective might differ from (1) by the discount factor $\widetilde{\beta} \in(0,1)$. Specifically, we allow for the case where the government discounts future periods at a higher rate than society does (see Grossmann and van Huyck, 1998): $\widetilde{\beta} \leq \beta$. When $\widetilde{\beta}<\beta$, the government acts in a myopic way, which can be rationalized by assuming that the government faces a constant probability of being in office $\varrho \in(0,1)$, where $\widetilde{\beta}=\varrho \beta$. According to this interpretation, the government's time horizon ends with its term in office, where $1 /(1-\varrho)$ measures the expected incumbency. When the government is myopic, $\widetilde{\beta}<\beta$, it will tend to overborrow, i.e. government indebtedness will tend to be larger than for $\widetilde{\beta}=\beta .^{8}$ Hence, lack of commitment and myopia provide two sources of inefficiency that originate in the government's behavior.

Following the literature on sovereign default, a default is assumed to include no new debt issuance in the same period. Hence, in each period the government trades off to repay outstanding debt $\left(p_{t}=1\right)$ and to issue new debt, which implies raising sufficiently large surpluses, or to fully default on outstanding debt $\left(p_{t}=0\right)$ and to run a zero primary surplus. We can summarize the government's budget constraint as

$$
p_{t} \cdot\left[q_{t} b_{t}-b_{t-1}\right]=-s_{t},
$$

where $p_{t} \in\{0,1\}$ and public debt $b_{t}$ is either held by households $b_{t}=b_{t}^{h}$ or by the fund $b_{t}=b_{t}^{b}$ if the government accepts the conditional loan of the fund. Subsequent to a period where the government has defaulted, it will regain access to credit, which differs from the assumption of permanent or temporary autarky subsequent to a default that is typically made in the literature on sovereign default in open economies (see Eaton and Gersovitz, 1981, or Arellano, 2008). Here, direct costs of default are just due to resource costs modelled according to (6).

To account for the government's discrete choice, we define $V_{t}^{c}$ as the maximum value under full repayment of debt (regardless whether it is held by households or the fund), $V_{t}^{d}$ as the maximum value under default, and $V_{t}^{b}$ as the maximum value when the government accepts the conditional loan. Then, the discrete debt repayment choice of the optimizing

\footnotetext{
${ }^{8}$ Note that this relates to Arellano's (2008) assumption that the inverse of the domestic country's discount factor differs from the world interest rate.
} 
government satisfies

$$
p_{t}=\left\{\begin{array}{l}
1 \text { if } V_{t}^{d} \leq \min \left\{V_{t}^{c}, V_{t}^{b}\right\} \\
0 \text { if } V_{t}^{d}>\max \left\{V_{t}^{c}, V_{t}^{b}\right\}
\end{array},\right.
$$

while the solution to the complete government problem is characterized by the maximum achievable value $V_{t}$ :

$$
V\left(b_{t-1}, a_{t}\right)=\max \left\{V^{c}\left(b_{t-1}, a_{t}\right), V^{d}\left(a_{t}\right), V^{b}\left(b_{t-1}, a_{t}\right)\right\}
$$

When the government decides to accept a conditional loan, $V_{t}^{b}>\max \left\{V_{t}^{c}, V_{t}^{d}\right\}$, it has to choose taxes and spending to satisfy (7) which, together with the government budget constraint, $\left(b_{t}^{b} / R_{t}^{r f}\right)+s_{t}=b_{t-1}$, implies the end-of-period stock of debt to satisfy $b_{t}^{b} \leq \kappa_{t} b_{t-1}$, where $\kappa_{t}=1 /\left(\Psi+1 / R_{t}^{r f}\right)$ is the borrowing ratio that relates the maximum amount of new debt the government is allowed to issue under the conditional loan to the level of initially outstanding debt. To give a preview, the borrowing ratio will be constant in the quantitative analysis (since $R_{t}^{r f}$ will be constant), while - for all parameterizations under consideration the fiscal constraint $(7)$ is found to hold with equality $\left(b_{t}^{b}=\kappa b_{t-1}\right)$ when the fund's offer is accepted. Once the government accepts the offer, it will exclusively borrow from the fund, given that its loans exhibit a favorable interest rate, $R_{t}^{r f} \leq R_{t}$.

\subsection{Equilibrium}

We examine Markov perfect equilibria, where expectations of private agents and the behavior of the optimizing government are consistent and where the government moves first in each period. The state of the economy can be summarized by the beginning-of-period stock of government bonds $b_{t-1}$ (either held by the household sector or the fund) and the exogenous productivity level $a_{t}$. Let $\Lambda\left(b_{t-1}\right)$ be the set of values for the exogenous state $a_{t}$ where the government prefers to default, $\digamma\left(b_{t-1}\right)$ the set of values for $a_{t}$ where the government prefers to accept the conditional loan, and $\Theta\left(b_{t-1}\right)$ the set of values for $a_{t}$ where the government prefers to fully repay debt:

$$
\begin{aligned}
& \Lambda\left(b_{t-1}\right)=\left\{a_{t} \in \Upsilon: V^{d}\left(a_{t}\right)>\max \left\{V^{b}\left(a_{t}, b_{t-1}\right), V^{c}\left(a_{t}, b_{t-1}\right)\right\}\right\}, \\
& \digamma\left(b_{t-1}\right)=\left\{a_{t} \in \Upsilon: V^{b}\left(a_{t}, b_{t-1}\right) \geq \max \left\{V^{d}\left(a_{t}\right), V^{c}\left(a_{t}, b_{t-1}\right)\right\}\right\}, \\
& \Theta\left(b_{t-1}\right)=\left\{a_{t} \in \Upsilon: V^{c}\left(a_{t}, b_{t-1}\right) \geq \max \left\{V^{d}\left(a_{t}\right), V^{b}\left(a_{t}, b_{t-1}\right)\right\}\right\} .
\end{aligned}
$$

The expected default rate is thus given by $E_{t} \delta_{t+1}=\sum_{a_{t+1} \in \Lambda\left(b_{t}\right)} \pi\left(a_{t+1} \mid a_{t}\right)$. Further, $q_{t}$ denotes the period $t$ price of government bonds, which either equals $1 / R_{t}$ if the government borrows from households or $1 / R_{t}^{r f}$ if it accepts a conditional loan, $q_{t} \in\left\{1 / R_{t}, 1 / R_{t}^{r f}\right\}$. Using 
that goods and asset markets clear, $y_{t}=c_{t}+g_{t}$, the private sector equilibrium behavior can then be summarized as follows:

$$
\begin{aligned}
-u_{l}\left(c_{t}, g_{t}, l_{t}\right) & =\Xi\left(a_{t}, p_{t}\right) f^{\prime}\left(l_{t}\right) u_{c}\left(c_{t}, g_{t}, l_{t}\right)\left(1-\tau_{t}\right), \\
q_{t} u_{c}\left(c_{t}, g_{t}, l_{t}\right) & =\beta E_{t}\left[\left(1-\delta_{t+1}\right) u_{c}\left(c_{t+1}, g_{t+1}, l_{t+1}\right)\right], \\
c_{t}+g_{t} & =\Xi\left(a_{t}, p_{t}\right) f\left(l_{t}\right), \\
E_{t}\left(1-\delta_{t+1}\right) & =1-\sum_{a_{t+1} \in \Lambda\left(b_{t}\right)} \pi\left(a_{t+1} \mid a_{t}\right),
\end{aligned}
$$

and the transversality conditions. Note that the latter rule out Ponzi-games of the fund. The government has to satisfy

$$
g_{t}-\tau_{t} \Xi\left(a_{t}, p_{t}\right) f^{\prime}\left(l_{t}\right) l_{t}=\left\{\begin{array}{cc}
q_{t} b_{t}-b_{t-1} \forall a_{t} \in \Theta\left(b_{t-1}\right) \cup \digamma\left(b_{t-1}\right) \\
0 & \forall a_{t} \in \Lambda\left(b_{t-1}\right)
\end{array},\right.
$$

where $b_{t}=b_{t}^{h}$ or $b_{t}=b_{t}^{b}$ if it accepts the conditional loan. As described above, the government aims at maximizing its objective (see 8 ) by choosing $\tau_{t}, g_{t}$, and $b_{t}$ on a period by period basis. The choice for these instruments further depends on the government's discrete choice to repay debt, to default, or to accept the conditional loan. For the full repayment case, the optimal government choice satisfies $p_{t}=1$ and

$$
\begin{aligned}
& V^{c}\left(b_{t-1}, a_{t}\right)=\max _{c_{t}, l_{t}, \tau_{t}, g_{t}, b_{t}}\left\{u\left(c_{t}, g_{t}, l_{t}\right)+\widetilde{\beta} \sum_{a_{t+1}} V\left(b_{t}, a_{t+1}\right) \pi\left(a_{t+1} \mid a_{t}\right)\right\} \\
& \text { s.t. (13)-(16), and } g_{t}-\tau_{t} \Xi\left(a_{t}, 1\right) f^{\prime}\left(l_{t}\right) l_{t}=\left(b_{t} / R_{t}\right)-b_{t-1} .
\end{aligned}
$$

In the default case, $p_{t}=0$, the government cannot borrow in period $t, b_{t}=0$, while it regains access to the credit market in period $t+1$. Hence, its problem can be written as

$$
V^{d}\left(a_{t}\right)=\max _{c_{t}, l_{t}, \tau_{t}, g_{t}}\left\{u\left(c_{t}, g_{t}, l_{t}\right)+\widetilde{\beta} \sum_{a_{t+1}} V\left(0, a_{t+1}\right) \pi\left(a_{t+1} \mid a_{t}\right)\right\}
$$

s.t. $(13),(15)$, and $g_{t}=\tau_{t} \Xi\left(a_{t}, 0\right) f^{\prime}\left(l_{t}\right) l_{t}$,

where the continuation value accounts for access to the credit market subsequent to the default period. As described in Section 2.2, we assume that the fund behaves in a pre-specified way. The price of the conditional loan is set equal to the risk-free price and the tightness $\Psi$ of the fiscal constraint (7) is varied over a range of values. The government's decisions under 
conditional loans satisfy $p_{t}=1$ and

$$
V^{b}\left(b_{t-1}, a_{t}\right)=\max _{c_{t}, l_{t}, \tau_{t}, g_{t}, b_{t}}\left\{u\left(c_{t}, g_{t}, l_{t}\right)+\widetilde{\beta} \sum_{a_{t+1}} V\left(b_{t}, a_{t+1}\right) \pi\left(a_{t+1} \mid a_{t}\right)\right\},
$$

s.t. $(13),(15), g_{t}-\tau_{t} \Xi\left(a_{t}, 1\right) f^{\prime}\left(l_{t}\right) l_{t}=\left(b_{t} / R_{t}^{r f}\right)-b_{t-1}$, and $b_{t} \leq\left[1 /\left(\Psi+1 / R_{t}^{r f}\right)\right] b_{t-1}$,

where $1 / R_{t}^{r f}$ and $\Psi$ are taken as given. The maximum value $V\left(b_{t-1}, a_{t}\right)$ is then given by (11). Notably, the government takes the fund's offer fully into account in every period, regardless of previous decisions. An equilibrium can then be defined as follows:

Definition 1 A Markov perfect equilibrium is a set of policy functions $c_{t}=c\left(b_{t-1}, a_{t}\right)$, $l_{t}=l\left(b_{t-1}, a_{t}\right), b_{t}=b\left(b_{t-1}, a_{t}\right), \tau_{t}=\tau\left(b_{t-1}, a_{t}\right), g_{t}=g\left(b_{t-1}, a_{t}\right), E_{t} \delta_{t+1}=\delta\left(b_{t-1}, a_{t}\right)$, the bond price $q_{t}=q\left(b_{t}, a_{t}\right)$, a discrete decision $p_{t}=p\left(b_{t-1}, a_{t}\right)$, as well as $V\left(b_{t-1}, a_{t}\right), V^{d}\left(a_{t}\right)$, $V^{c}\left(b_{t-1}, a_{t}\right)$, and $V^{b}\left(b_{t-1}, a_{t}\right)$ satisfying (10), (11), (13)-(20).

\section{$3 \quad$ Fiscal policy choices}

In this section, we discuss the government's choices with a particular focus on the case where default costs are prohibitively high. For quasi-linear preferences, i.e. $u_{c c}=0$, and without myopia, we show that the allocation is then identical to an optimal policy under commitment (see Appendix A), implying that lack of commitment per se does not lead to a suboptimal policy. Yet, lack of commitment leads to a policy that can differ from the policy under commitment if there exists a relevant default option, i.e. if default costs are not prohibitively high. For the subsequent numerical analysis we therefore assume that $u_{c c}=0$, implying that welfare losses can be attributed to default and myopia, providing a rationale for the proposed specification of conditional bailouts. ${ }^{9}$

Consider the general case where $u_{c c} \leq 0$. Under full debt repayment, $p_{t}=1$, the government problem is summarized by (18). Eliminating consumption and the bond price, the government's problem reduces to choices of the tax rate, expenditures, working time, and public debt. The first order conditions with regard to the first three choices can be written

\footnotetext{
${ }^{9}$ It should be noted that the assumption of risk-neutral investors is shared by the majority of studies on sovereign default, while a quasi-linear utility function of domestic households is also applied in Cole and Kehoe's (2000) analysis of sovereign default.
} 


$$
\begin{aligned}
& \mu_{t} \Xi_{t} f^{\prime}\left(l_{t}\right)=\gamma_{t} \Xi_{t} f^{\prime}\left(l_{t}\right) l_{t}, \\
& u_{c, t} \gamma_{t}=u_{g, t}+u_{c c, t} \mu_{t}\left(u_{l, t} / u_{c, t}^{2}\right)+\left[u_{c c, t} \gamma_{t}\left(b_{t} / u_{c, t}^{2}\right) \beta E_{t}\left(\left(1-\delta_{t+1}\right) u_{c, t+1}\right)\right], \\
& u_{c, t} \Xi_{t} f_{t}^{\prime}+u_{l, t}+\mu_{t}\left(u_{l l, t} / u_{c, t}\right)+\mu_{t}\left(1-\tau_{t}\right) \Xi_{t} f^{\prime \prime}\left(l_{t}\right)+\gamma_{t} \tau_{t} \Xi_{t}\left(f^{\prime}\left(l_{t}\right)+f^{\prime \prime}\left(l_{t}\right) l_{t}\right) \\
= & u_{c c, t} \mu_{t} \Xi_{t} f_{t}^{\prime}\left(u_{l, t} / u_{c, t}^{2}\right)+\left[u_{c c, t} \gamma_{t} \Xi_{t} f_{t}^{\prime}\left(b_{t} / u_{c, t}^{2}\right) \beta E_{t}\left(\left(1-\delta_{t+1}\right) u_{c, t+1}\right)\right],
\end{aligned}
$$

where $\Xi_{t}=\Xi\left(a_{t}, 1\right)$ and $E_{t}\left(1-\delta_{t+1}\right)=1-\sum_{a_{t+1} \in \Lambda\left(b_{t}\right)} \pi\left(a_{t+1} \mid a_{t}\right)$ and $\mu_{t}$ and $\gamma_{t}$ denote the multipliers for the constraints $u_{l, t} /\left[u_{c, t}\left(\Xi_{t} f\left(l_{t}\right)-g_{t}\right)\right]+\left(1-\tau_{t}\right) \Xi_{t} f^{\prime}\left(l_{t}\right)=0$ and $\tau_{t} \Xi_{t} f^{\prime}\left(l_{t}\right) l_{t}-$ $g_{t}+\beta E_{t} \frac{\left[\left(1-\delta_{t+1}\right) u_{c, t+1}\left(\Xi_{t+1} f\left(l_{t+1}\right)-g_{t+1}\right)\right]}{u_{c, t}\left(\Xi_{t} f\left(l_{t}\right)-g_{t}\right)} b_{t}=b_{t-1}$. The government's decision further satisfies an optimal choice for newly issued debt $b_{t}$, where the government accounts for the equilibrium impact of $b_{t}$ on the expected repayment rate and - possibly - on the households' consumption decision in the subsequent period (see below).

For the case where the government decides to default, $p_{t}=0$, its problem is given by (19). The first order conditions for the government's choice of the tax rate, expenditures, and working time are then identical to (21)-(23), expect for $\Xi_{t}=\Xi\left(a_{t}, 0\right)$ and for the terms in the square brackets in (22) and (23), which account for the policy impact on the bond price and vanish under default. It should be noted that the government's first order conditions under repayment and default are identical if the marginal utility of consumption is constant, $u_{c c, t}=0$.

To be eligible for bailout loans at the favorable price $1 / R_{t}^{r f}$, the government has to satisfy two conditions. First, it has to repay previous debt $\left(p_{t}=1\right)$ and, second, it has to raise surpluses in the current period to comply with the fiscal constraint (7). Given that end of period debt then has to satisfy $b_{t} \leq \kappa b_{t-1}$, the tax and spending choices are restricted by $\tau_{t} a_{t} \alpha l_{t}^{\alpha}-g_{t} \geq b_{t-1} /\left[1+1 /\left(R_{t}^{r f} \Psi\right)\right]$, while the first order conditions with regard to the tax rate and government expenditures are again given by (21) and (22).

Now suppose that default costs are prohibitively high, $\Xi\left(a_{t}, 0\right) \rightarrow 0$. Then, default implies that no resources are available for private and public consumption, such that $V^{d}\left(b_{t-1}, a_{t}\right) \rightarrow$ $-\infty$ (see 19)). Hence, the government repays debt in all states, such that the default set is empty $\Lambda\left(b_{t-1}\right)=\varnothing$. Given that the default probability then equals zero, the price of debt $q_{t}$ equals the inverse of the risk-free rate $1 / R_{t}^{r f}$ (see 4 and 5 ). This case therefore corresponds to a fiscal policy without commitment, where debt is repaid in all states, as for example analyzed in Krusell et al. (2006) or Debortoli and Nunes (2013). The government's choice for newly issued debt then satisfies the first order condition $\Xi\left(a_{t}, 0\right) \rightarrow 0: \gamma_{t}\left[q_{t}+\beta E_{t}\left(\frac{u_{c c, t+1}}{u_{c, t}} \frac{\partial c_{t+1}}{\partial b_{t}}\right) b_{t}\right]=$ $\widetilde{\beta} E_{t} \gamma_{t+1}$, where the derivative $\partial c_{t+1} / \partial b_{t}$ accounts for the impact of debt issued in period $t$ on 
the consumption decision of households in period $t+1$. As shown by Debortoli and Nunes (2013) for $\widetilde{\beta}=\beta$ in a closely related environment, public debt then converges to a mean level of zero. To account for public debt accumulation and for plausible default probabilities, we therefore focus - for the subsequent analysis - on the case where the government acts in a myopic way, i.e. $\widetilde{\beta}<\beta$, which tends to increase public borrowing (since the market price $1 / R_{t}$ exceeds the government's marginal valuation of debt).

The case of a non-myopic government provides a useful reference case for the subsequent analysis. It can be shown that the government's choice under lack of commitment is then identical to the case of full commitment (see Appendix A), when the utility function is quasilinear, $u_{c c}=0$. Then, there evidently exists no justification for bailouts or fiscal constraints, since fiscal policy is conducted in an optimal way when the default option is irrelevant. This property is summarized in the following proposition.

Proposition 1 Suppose that default costs are prohibitively high such that the default set is empty $\Lambda\left(b_{t-1}\right)=\varnothing$ and that the government is non-myopic, $\widetilde{\beta}=\beta$. The allocation under $a$ fiscal policy without commitment is then identical to the optimal allocation under commitment if the utility function satisfies $u_{c c}=0$.

\section{Proof. See Appendix A}

When the marginal utility of consumption is constant, $u_{c c}=0$, the government's first order condition for debt issuance reduces for $\widetilde{\beta}=\beta$ to $\gamma_{t} q_{t}=\beta E_{t} \gamma_{t+1}$. Together with (4), which implies $q_{t}=\beta$ for $\Lambda\left(b_{t-1}\right)=\varnothing$, the latter reveals the well-known random-walk property under optimal fiscal policy with non-state-contingent debt, $\gamma_{t}=E_{t} \gamma_{t+1}$. For $u_{c c}=0$, the remaining government choices under commitment and without commitment are also identical, as shown in the proof of Proposition 1.

If, however, default costs are not prohibitively high, the default set can be non-empty, $\Lambda\left(b_{t-1}\right) \neq \varnothing$. Then, the price of government bonds will in general be a function of public debt, i.e. $\partial q_{t} / \partial b_{t} \neq 0$, even if $u_{c c, t}=0$. Discretionary fiscal policy then differs from the optimal fiscal policy under commitment, while the difference is aggravated with higher degrees of government myopia. Hence, this scenario leaves room for welfare improvements via conditional loans (as specified in Section 2.2), which can in principle avert default and address adverse effects of myopia by offering a favorable price conditional upon a fiscal constraint (7).

\section{Results}

This section presents the numerical results. The first part introduces the functional forms for preferences and technology which simplify the government's problem substantially (see Appendix B), as well as the parametrization of the model. In the second part of this section, 
we describe how government choices, the equilibrium allocation, and bond prices change with the state of the economy for a benchmark version of the model where no bailout is offered. In the third part, we introduce conditional loan offers, show that they serve as bailouts, and compute main statistics of model simulations for fiscal constraints (7) that differ with regard to the tightness.

\subsection{Functional forms and calibration}

Given that the government faces a discrete choice, the model is solved numerically using value function iteration (see Appendix $\mathrm{C}$ ). We introduce the following specifications for the household preferences $u_{t}$, for the default costs $\Xi_{t}$, and the production technology $y_{t}=\Xi_{t} f\left(l_{t}\right)$ :

$$
\begin{aligned}
u\left(c_{t}, g_{t}, l_{t}\right) & =\psi c_{t}+\left[\left(g_{t}^{1-\sigma}-1\right) /(1-\sigma)\right]-\vartheta l_{t}^{1+\eta} /(1+\eta), \\
\Xi_{t} & =\left\{\begin{array}{cc}
a_{t} & \forall a_{t} \in \Theta\left(b_{t-1}\right) \cup \digamma\left(b_{t-1}\right) \\
\underline{a}<a_{t} & \forall a_{t} \in \Lambda\left(b_{t-1}\right)
\end{array},\right. \\
f\left(l_{t}\right) & =l_{t}^{\alpha},
\end{aligned}
$$

where the utility function (24) is quasi-linear, satisfying $u_{c c, t}=0$ as considered in Proposition 1 and implying a constant risk-free rate $R_{t}^{r f}=1 / \beta$ as well as no wealth effects on labor supply. The deterministic part of the production function (26) is standard. According to the specification of the effective productivity $\Xi_{t}$ (see 25), $a_{t}$ together with $f\left(l_{t}\right)$ determines total output in states where the government decides to fully repay debt, $a_{t} \in \Theta\left(b_{t-1}\right)$. If the government defaults in a particular state $\widetilde{a}_{t} \in \Lambda\left(b_{t-1}\right)$, total output equals $\underline{a} f\left(l\left(b_{t-1}, \underline{a}\right)\right)$, which is less than $\widetilde{a}_{t} f\left(l\left(b_{t-1}, \widetilde{a}_{t}\right)\right)$. Hence, (25) induces aggregate resource costs of default. To allow for sufficiently high costs of default so that default probabilities take reasonable values, we truncate productivity in default states at the smallest productivity level in the productivity set $\Upsilon$, which induces default to be more costly in higher productivity states (as in Arellano, 2008, or Cuadra et al., 2010).

Throughout the numerical analysis, we set the technology and preference parameters $\{\alpha$, $\beta, \sigma, \eta\}$ to values which are standard in the business cycle literature: $\alpha=2 / 3, \sigma=2$, $\eta=2$, and $\beta=0.99$ (implying an annual risk-free rate of $4.1 \%$ ). The remaining parameters, including $\psi=6$ and $\vartheta=0.25$, are chosen to match average government shares and output dynamics of a set of European countries which are highly indebted and have recently experienced a surge in default risk premia. Specifically, we consider average statistics for Greece, Italy, Portugal, and Spain. We set the autocorrelation of productivity to 0.9 and choose the innovation variance $\sigma_{\varepsilon}^{2}$ such that the realized standard deviation of log output from stochas- 
tically simulated model runs conforms with the average standard deviation of HP-filtered log real quarterly GDP for the countries that we consider. The data is taken from the OECD National Accounts Statistics for the period 1970.I-2011.I and are seasonally adjusted by the publishing institution. The standard deviations of detrended log output range from 0.013 to 0.027 with a mean value of 0.019 , which we use as a calibration target for our model.

Using data from Eurostat's annual national accounts for the sample period 1995 to 2010, the government share is measured as the ratio of government consumption over GDP. The average value for the government share in our sample of countries is about 0.19. This value is applied as a calibration target, which is associated with an average tax rate under optimizing fiscal policy that amounts to 0.28. This endogenous value is comparable to an empirical measure of an average tax rate. ${ }^{10}$ The final parameter to be specified is the degree of myopia by the government, $\tilde{\beta}$. Since this parameter directly impacts on the borrowing behavior of the government it alters the realized default probability. Our baseline value is $\tilde{\beta}=0.9$ which implies an expected incumbency of 11 years and leads to a realized default probability of about $1 \%$. We use further values for the government's discount factor, $\tilde{\beta}=0.84$ and $\tilde{\beta}=0.96$ (corresponding to expected incumbencies of 6.6 and 33 years), to disclose the main effects for different degrees of overborrowing. ${ }^{11}$

\subsection{Sovereign default without conditional loans}

To see how the bailouts can be rationalized and to disclose the main incentives of the government, we focus in this Section on the case without conditional loans, which is identical to the case where loans are offered conditional upon fiscal constraints that are too tight to be acceptable by the government, e.g. for a borrowing ratio $\kappa=0$.

Figure 4.2 shows main properties of the government's behavior for different degrees of myopia, i.e. for three different values of its discount factor, $\widetilde{\beta} \in\{0.84,0.9,0.96\}$, which are all smaller than the household discount factor $(\beta=0.99)$. The panels in the first line show combinations of states $\left(a=a_{t}, b=b_{t-1}\right)$ for which the government either decides to fully repay debt $\left(V^{d} \leq V^{c}\right.$ : white region) or chooses to default $\left(V^{d}>V^{c}\right.$ : gray region). ${ }^{12}$ In order to ease exposition using two-dimensional figures, we consider two specific values of productivity, which differ from the mean productivity level by $+/-$ one standard deviation.

\footnotetext{
${ }^{10}$ When social security contributions are excluded, the ratio of total tax revenues over GDP amounts to 0.23 for the group of countries we consider. When taking social security contributions into account, the empirical figures are higher.

${ }^{11}$ Additional results for alternative parametrizations are available on request.

${ }^{12}$ To lighten the notation, we drop the time index and define $a=a_{t}, a^{\prime}=a_{t+1}, b=b_{t-1}$ and $b^{\prime}=b_{t}$ (as well as $q=q_{t}, g=g_{t}, \tau=\tau_{t}, l=l_{t}$ )
} 

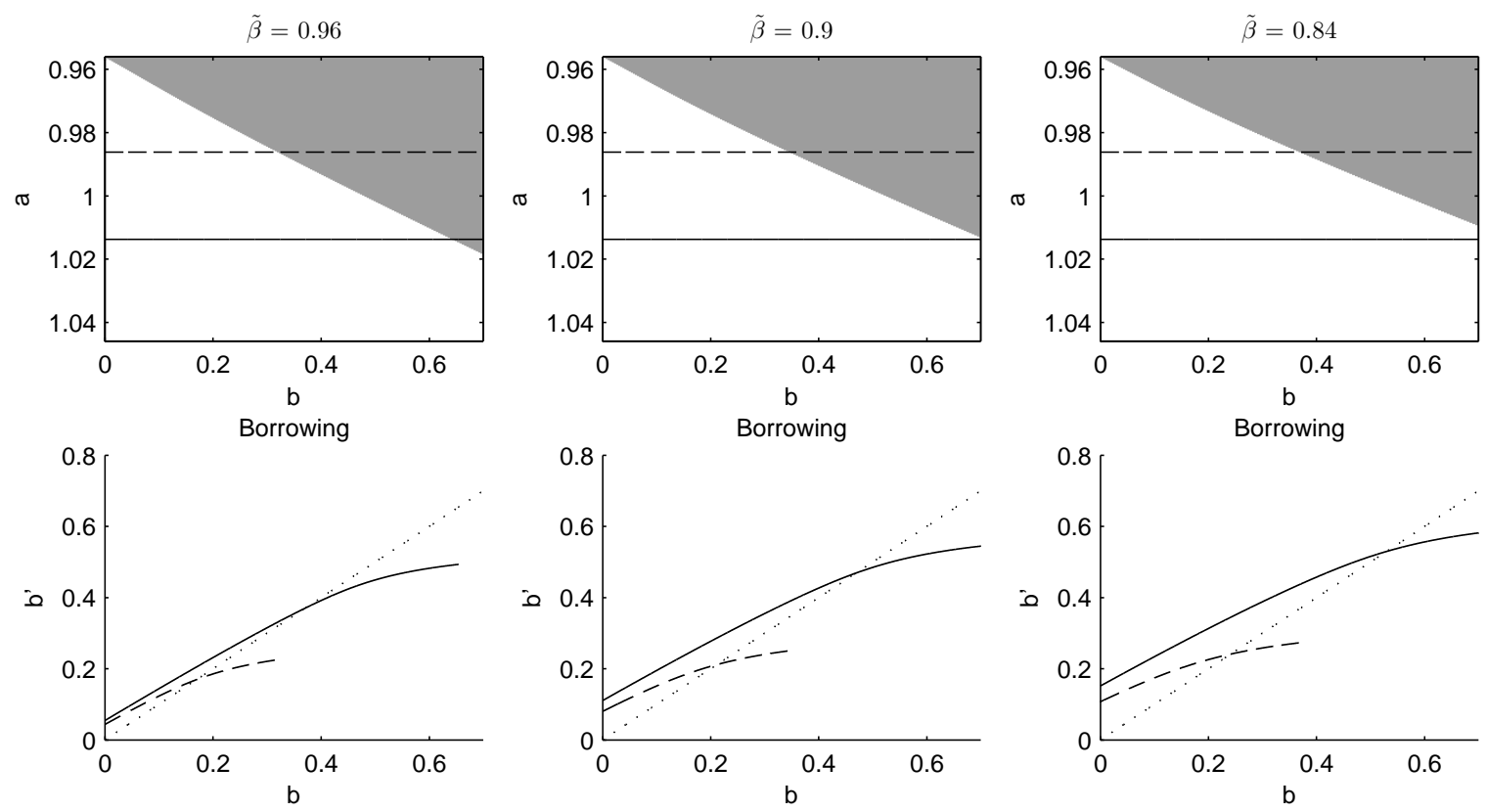

Figure 1: Default states (grey area) and borrowing functions for $\tilde{\beta}=\{0.84,0.9,0.96\}$

We refer to these values as "low" (dashed line) and "high" (solid line) productivity. The three panels in the first line show that the government tends to favor default when debt is high and productivity is low. For higher stocks of non-repaid debt gains from defaulting are larger, while default is relatively more costly for higher productivity levels. ${ }^{13}$ A closer look at the high productivity case (solid line) reveals that the government tends to default less in high productivity states when it is more myopic (graphically, the grey region shifts upward when $\widetilde{\beta}$ is smaller). The reason is that a more myopic government assigns a relatively higher weight to the costs of default, which lead to direct resource losses in the current period, than to the gains of default, which are not only relevant in the current period but also reduce the burden of debt repayment in the subsequent period(s).

The second line of Figure 4.2 shows the government's borrowing function $b^{\prime}(b, a)$ for the two productivity levels. Overall, debt issuance $b^{\prime}$ is increasing in outstanding debt $b$ and in the value of productivity $a$. The dashed line corresponding to the low-productivity case shows that the government borrows only for relatively low levels of outstanding debt $b$. For higher levels of debt, the government decides to default (for states where default occurs the plot of the borrowing function ends since $b^{\prime}=0$ ). A comparison of the borrowing functions for different degrees of myopia confirms common expectations that a more myopic agent tends to borrow

\footnotetext{
${ }^{13}$ This property is mainly induced by the default costs structure and is shared by Arellano (2008) and related studies.
} 
(a) Default states

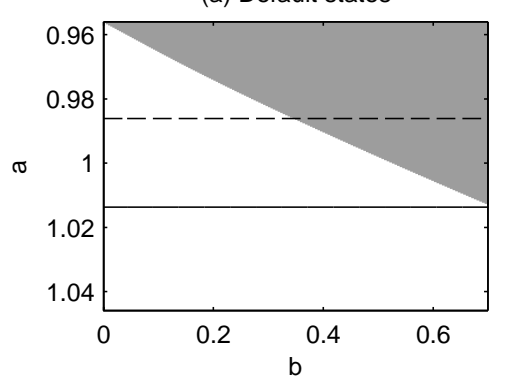

(d) Resources borrowed q(b') ${ }^{\star} b^{\prime}$

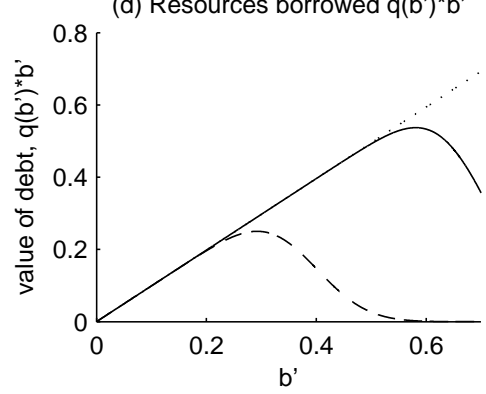

(g) Tax rate

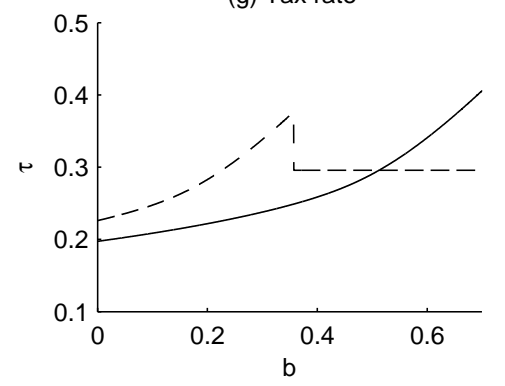

(b) Value function $\mathrm{V}(\mathrm{a}, \mathrm{b})$

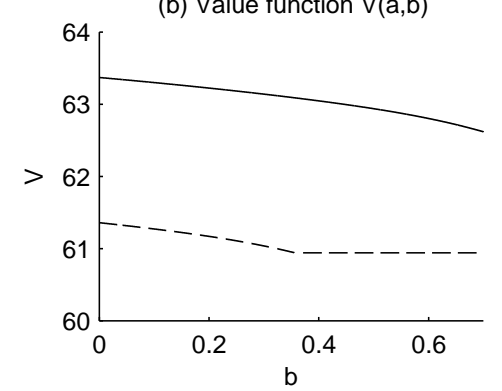

(e) Borrowing

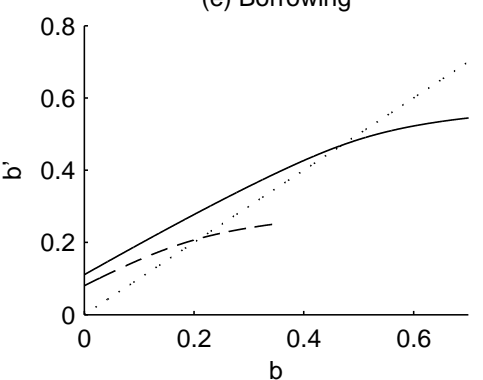

(h) Government spending

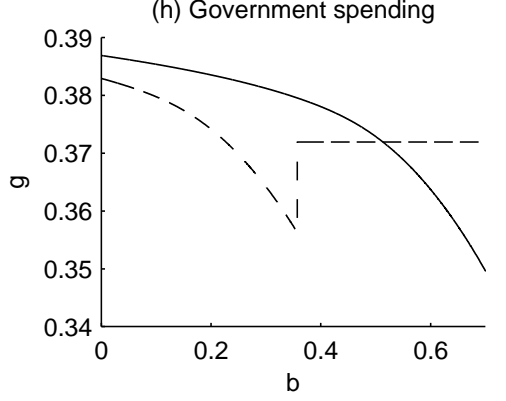

(c) Bond price schedule $q\left(a, b^{\prime}\right)$

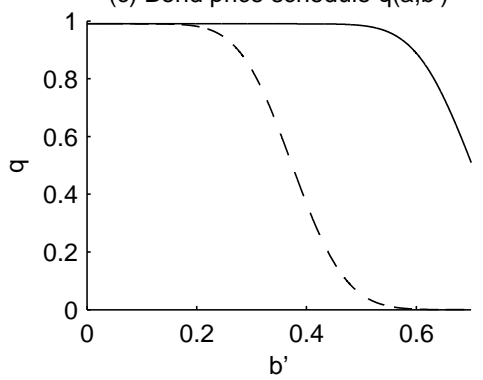

(f) Interest rate
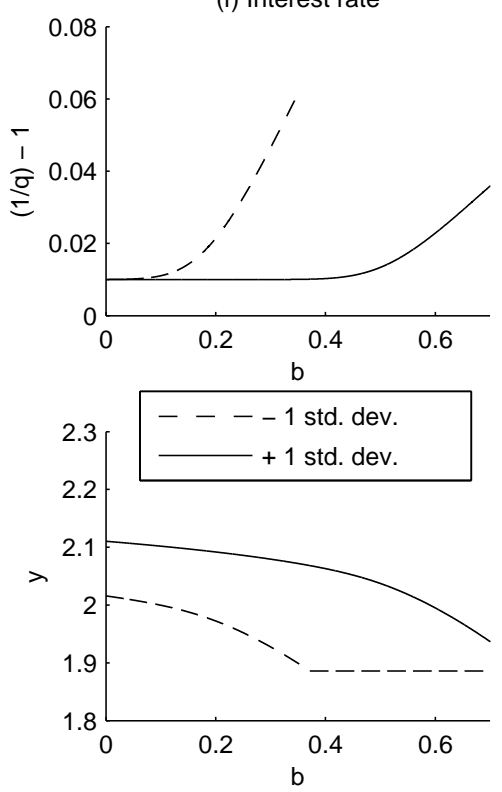

Figure 2: Selected policy functions for $\tilde{\beta}=0.9$

more (both curves shift upward when $\widetilde{\beta}$ is smaller). For the extreme case of a non-myopic government $(\widetilde{\beta}=\beta$, which is not displayed here), debt/productivity combinations that lie within the default region will therefore hardly ever be reached. However, the likelihood that default states are realized in equilibrium increases with the degree of myopia. This property is confirmed in the subsequent section, where the model is simulated for different values of $\widetilde{\beta}$ (see Figure 4.3).

Figure 4.2 displays further equilibrium objects for $\widetilde{\beta}=0.9$ as policy functions, i.e. as functions of the two state variables $a$ and $b$. Panel (a) and (e) again display the default states and the borrowing function, for convenience. Panel (b) shows the value functions $V(a, b)$ for high (solid) and low (dashed) values of current productivity $a$. In contrast to the value function for the case of high productivity, the value function for low productivity is kinked due to a switch from full repayment $V^{c}$ to default $V^{d}$, where $V^{d}$ does not depend on $b$. Panel (c) shows the equilibrium bond price $q\left(b^{\prime}, a\right)$, where $q$ is a function of next period debt $b^{\prime}$. 
When the productivity level is high, the government does not decide to default within the range of debt displayed in the graph. Accordingly, the government is able to borrow at the risk-free price $\beta$ for a wide range of values for $b^{\prime}$. When productivity is low, the bond price begins to decline already at very low levels of $b^{\prime}$. In fact, the bond price approaches zero when the government wants to issue high levels of debt, reflecting high default risk. Issuing bonds at a low price implies that the total amount of resources borrowed, i.e. the value of debt, $q b^{\prime}$, shrinks as $q$ declines. This can be seen in panel (d), which shows the value of debt $q b^{\prime}$ as a function of possible values for newly issued debt $b^{\prime}$.

The borrowing function $b^{\prime}(a, b)$ of the government is shown again in panel (e) and reveals that the government will not issue more debt than at the peak of the $q b^{\prime}$ curve (see panel (d)). Panel (f) shows that the interest rate $(1 / q)-1$ is increasing in debt due to increasing risk of default. The interest rate rises sharply when the economy approaches the default region, which encompasses more state combinations $(a, b)$ when the productivity level is low (dashed line). Panel $(\mathrm{g})$ and $(\mathrm{h})$ further show that the government tends to implement a higher primary surplus, by raising tax rates and reducing spending, when debt takes higher values and for lower values of productivity. The reason is that default risk is higher in less favorable states of the economy, such that the costs of borrowing increase for the government (see panel (c)). When the government decides to default, the burden of debt repayment is eliminated and the government substantially lowers tax rates and increases expenditures. Finally, panel (i) shows that output tends to decrease with debt due to the increase in the surplus. The kink in output (see dashed line) results from the productivity loss under default captured by $\Xi\left(a_{t}\right)$.

We further use stochastic model simulations to compute means of selected variables. For this, we simulate $N=10,000$ economies for $T=3,000$ periods each (initialized with zero debt and mean productivity), plus an additional burn-in period of 500 periods, which will not be used for the calculations. We compute means of variables conditional upon their realizations in periods prior to a default event. The simulation results, summarized in Figure 6 in Appendix E, show that defaults occur when productivity worsens. Prior to a default, the government raises taxes and reduces expenditures in response to increased costs of borrowing, which (qualitatively) relates to the austerity measures conducted by the Greece government before it was bailed out in May 2010. Subsequent to a default, where the output contraction is most pronounced, tax rates are reduced and government expenditures are raised, such that the government starts to accumulate debt again. These effects are more pronounced for higher degrees of myopia, where - on average - default occurs at higher debt and productivity 
levels.

We further compute household welfare for the three different degrees of myopia (all of which lead to non-zero default probabilities). The default option causes the price of debt to decrease with the debt level, such that the government's lack of commitment can become relevant for the ability to spread its financial burden over time. This property together with the direct costs induced by the default decision lead to welfare losses compared to the case of optimal fiscal policy. We approximate welfare (1) by computing the unconditional expectation of the sum of discounted household utility over the 3,000 periods, where the expectations are evaluated by averaging over the 10,000 samples, i.e. we compute $W=E \sum_{i=0}^{3000} \beta^{i} u\left(c_{t+i}, g_{t+i}, l_{t+i}\right)$ in permanent consumption equivalents, $\Delta c=\frac{1-\beta}{\psi} \Delta W$. As a reference case, we compute welfare for the optimal policy under commitment. For a nonmyopic government with lack of commitment, which will not be considered for the subsequent analysis as default is an extremely rare event $(<0.06 \%)$, welfare is virtually identical compared to the reference case of full commitment, $\left.\Delta c\right|_{\tilde{\beta}=\beta}=0.003 \%$. For the case of a myopic government that lacks commitment $(\tilde{\beta}=0.9)$, the welfare loss compared to the reference case equals $\left.\Delta c\right|_{\tilde{\beta}=0.9}=0.15 \%$, while for the alternative degrees of myopia $(\tilde{\beta}=0.84$ and $\tilde{\beta}=0.96)$, welfare losses amount to $\left.\Delta c\right|_{\tilde{\beta}=0.84}=0.21 \%$ and $\left.\Delta c\right|_{\tilde{\beta}=0.96}=0.08 \%$, indicating that welfare decreases with the degree of myopia.

\subsection{Effects of bailout loans}

For the analysis of conditional loans offered by the fund, we assume that the government and the private sector take the fund's offer fully into account in all states of the economy. To demonstrate the impact of the conditional loans, we vary the tightness of the fiscal constraint (7), which is crucial for the welfare and consolidation effects of the loans: ${ }^{14}$ On the one hand, tighter fiscal constraints, i.e. higher values for $\Psi$ or lower values for $\kappa=1 /(\Psi+\beta)$, demand a higher contemporaneous primary surplus, which exerts adverse effects on household utility by higher taxes rates or/and lower government expenditures. On the other hand, tighter fiscal constraints induce a more pronounced fiscal consolidation that allows reducing the primary surplus in the subsequent period(s). These two effects, which can analytically be shown for a two-period version of the model (see Appendix D), suggest that bailouts are likely to be most beneficial when the loan is offered under moderate conditionality.

Figure 4.3 shows state combinations for the discrete choice of the government, i.e. a repayment region, a default region, and a region where it accepts the offer (marked with the

\footnotetext{
${ }^{14}$ For all cases under consideration, the fiscal constraint is binding when the conditional loan is accepted.
} 

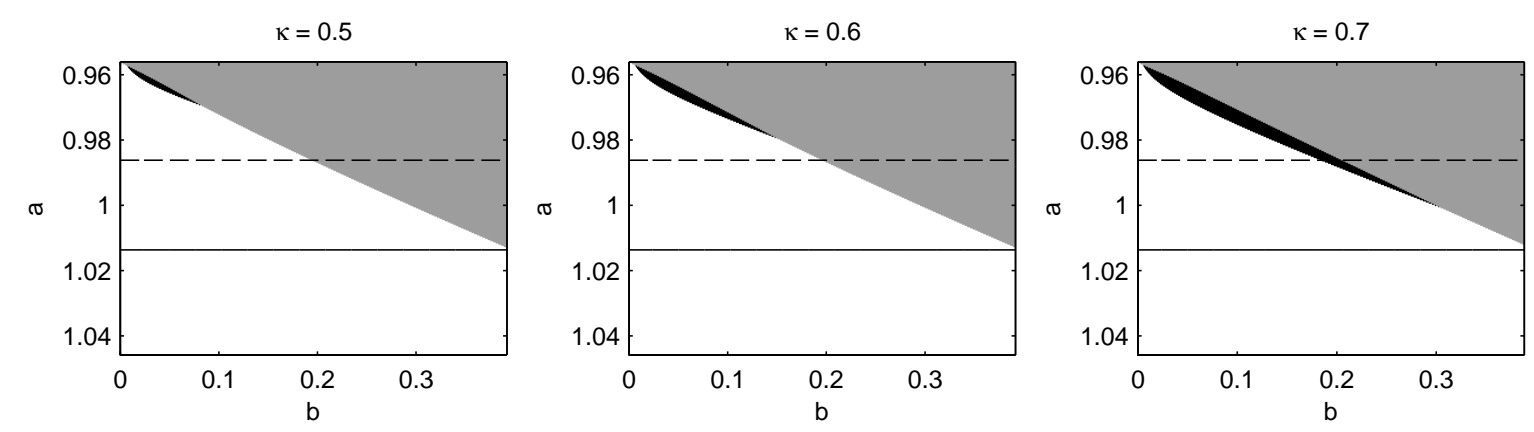

Figure 3: Default (grey area) and bailout states (black area) for $\kappa=\{0.5,0.6,0.7\}$

black area) for three values of $\kappa$, which governs the tightness of the fiscal constraint (7). For a tight fiscal constraint, $\kappa=0.5$ (i.e. the government is allowed to roll-over only $50 \%$ of outstanding debt), loans are accepted by the government when productivity is low and debt is at the boundary between full repayment and default. These are situations where interest rates on public debt are particularly high (see panel (f) in Figure 4.3 below), indicating that the conditional loans indeed serve as bailouts. Notably, conditional loans are mainly accepted in states where the government would be willing to repay if no conditional loan was offered. For higher productivity levels, the conditional loans are not attractive for the government and never accepted. Thus, conditional loans with a tight fiscal constraint tend to be less attractive when the government is more indebted, since the associated fiscal consolidation is relatively more pronounced than for lower debt levels. Even though conditional loans allow debt to be issued at a favorable price, a highly indebted government prefers defaulting, which allows to fully cut down the debt burden. The other graphs show repayment states, default states, and states where loans are accepted for less restrictive fiscal constraints, $\kappa=0.6$ and $\kappa=0.7$. Conditional loans are again only accepted at the boundary to the default states, while the debt range for which bailouts are realized increases with $\kappa$. Since fiscal constraints are now less severe, conditional loans can be favorable to default even for higher degrees of indebtedness and higher productivity levels. A closer look at the case $\kappa=0.7$ shows that a conditional loan can be the most attractive choice in states where the government would default otherwise (graphically, the gray region slightly shifts upwards), which is confirmed by the simulation results discussed below (see Figure 4.3). To summarize, conditional loans actually serve as bailouts of governments in adverse states, while they do not preclude default.

Figure 4.3 shows equilibrium objects as policy functions under conditional loans for $\kappa=$ 0.7 and is the counterpart to Figure 4.2, where no loans have been offered. The impact of bailouts can in particular be seen in panels (e) and (f), where the bold part of the lines 
(a) Default states

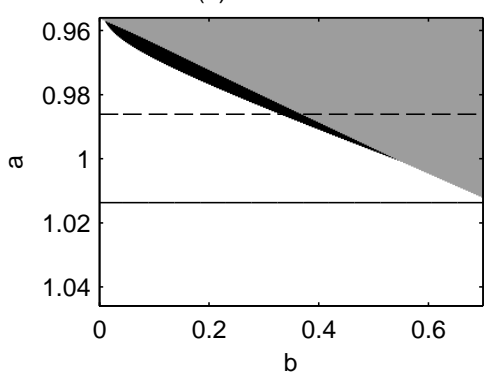

(d) Resources borrowed q(b')*b'

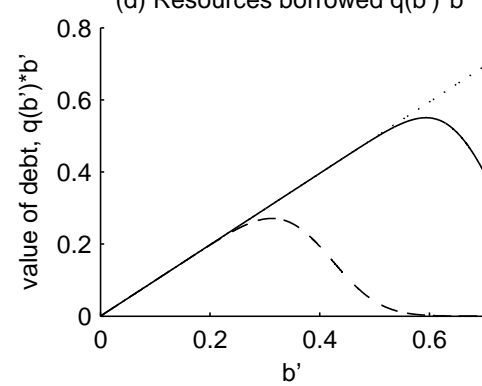

(g) Tax rate

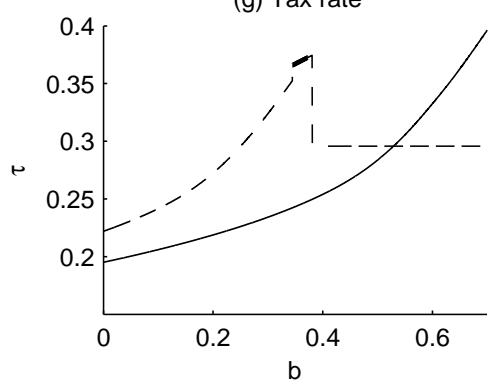

(b) Value function $\mathrm{V}(\mathrm{a}, \mathrm{b})$

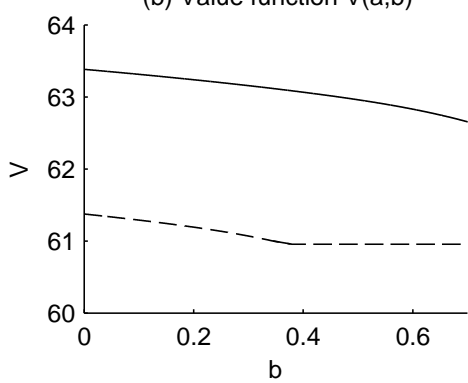

(e) Borrowing

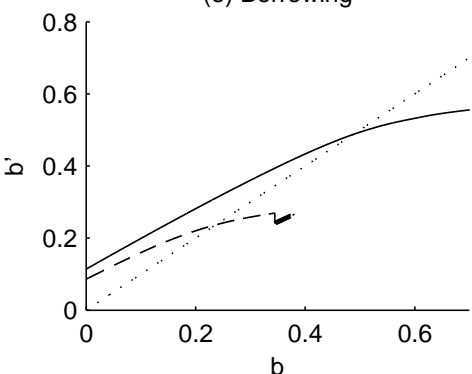

(h) Government spending

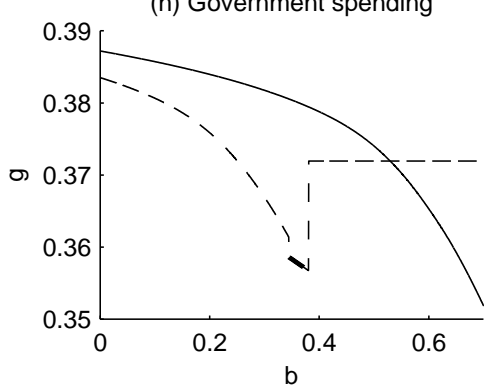

(c) Bond price schedule $q\left(a, b^{\prime}\right)$

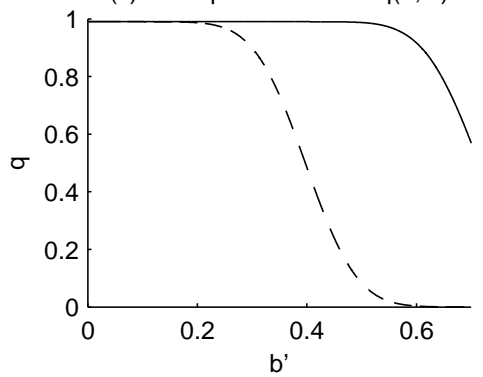

(f) Interest rate
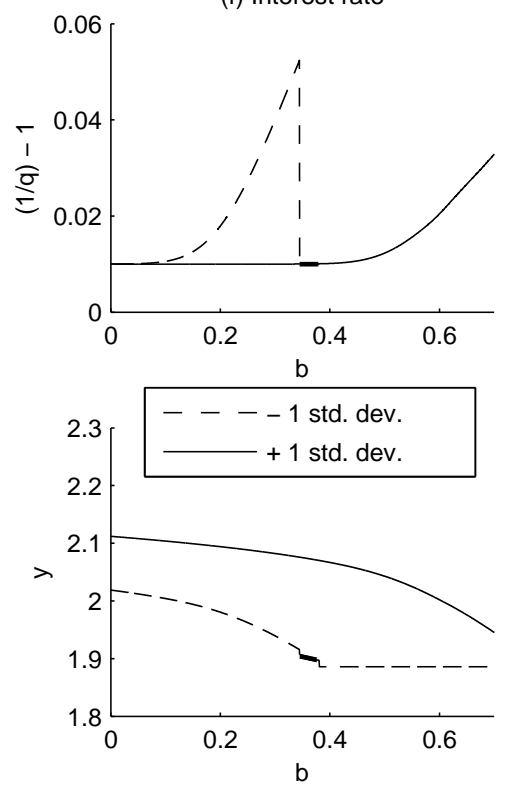

Figure 4: Selected policy functions for $\kappa=0.7$

highlight the cases where the conditional loan is accepted by the government. The government accepts loans and the associated conditionality when interest rates are high (see panel (f)) and the government is already forced to reduce borrowing due to very low debt prices (see panel (e)). By construction, the interest rate drops to the risk-free interest rate when conditional loans are accepted. Compared to the case without conditional loans, the bond price as well as government borrowing increase in all states (see Figure 7 in Appendix E). Under a bailout, the government can roll-over debt only up to a fraction $\kappa$ of its outstanding debt, implying a short-run fiscal consolidation (graphically, a downward shift of the borrowing curve in panel (e)). Panels (g) and (h) show that the government then has to raise taxes and to lower spending to satisfy the fiscal constraint imposed by the fund. This pattern is confirmed by stochastic simulations of the model, for which we compute the means of selected variables conditional upon their realization prior to a bailout (see Figure 8 in Appendix E). The results show that bailouts with $\kappa=0.7$ lead to a reduction in debt in the short-run, but are also 

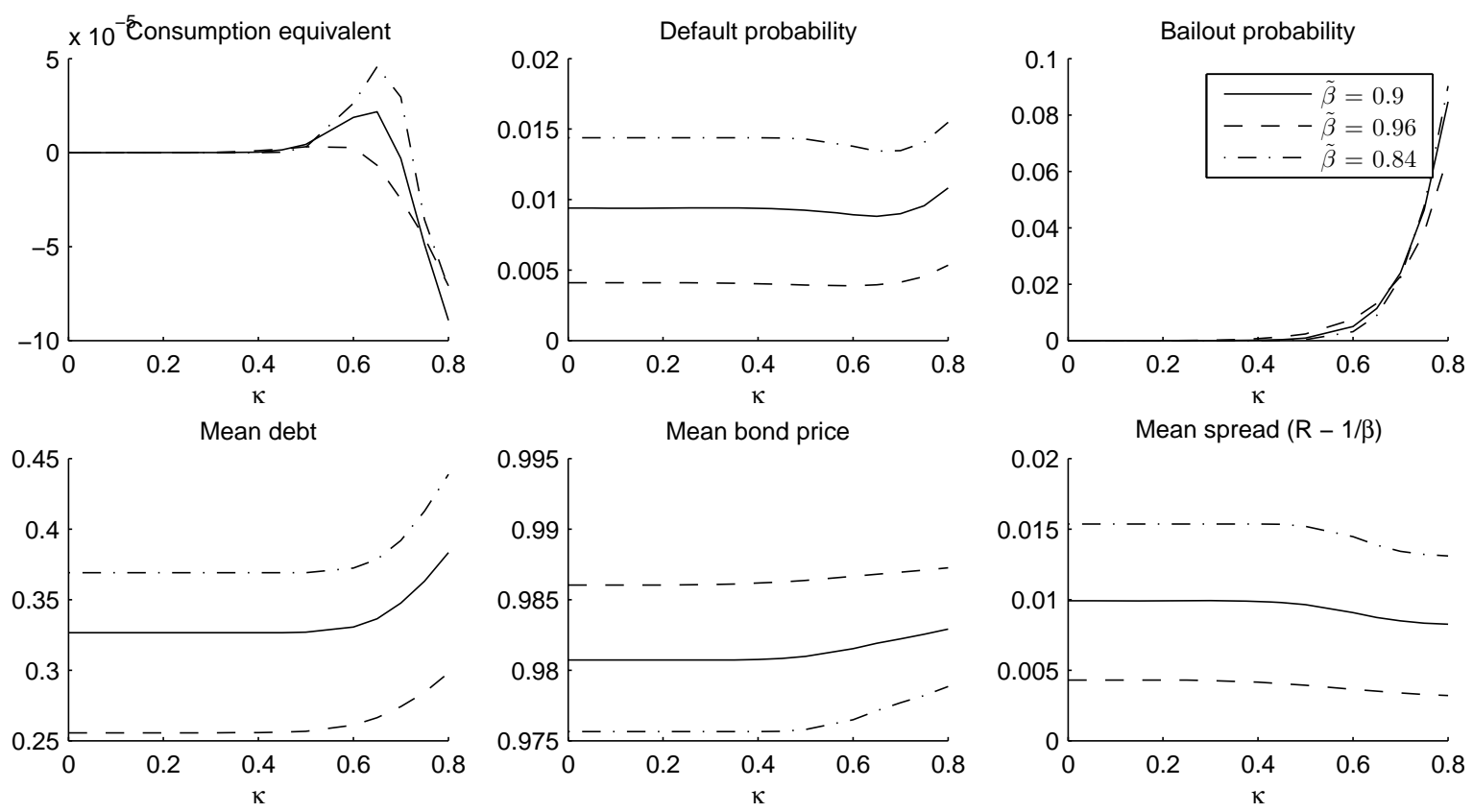

Figure 5: Sample statistics from model simulations for different degrees of myopia

accompanied by output contractions which are aggravated by the fiscal consolidation. These effects are more pronounced for a higher degree of myopia, where bailouts require larger surpluses due to higher initial debt levels.

Figure 4.3 presents simulation results for different degrees of myopia, $\widetilde{\beta} \in\{0.84,0.9,0.96\}$, under bailout loans that differ with regard to the tightness of the fiscal constraint $\kappa$. The solid lines refer to the case $\widetilde{\beta}=0.9$. For tight fiscal constraints, i.e. for low values of $\kappa$, the government is less willing to accept conditional bailout loans due to the costs induced by high taxation and low government spending. (The cases for $\kappa \rightarrow 0$ coincide with the case where bailout loans were not offered.) Higher values of $\kappa$, which indicate a less restrictive fiscal constraint, are more favorable for the government and can make the bailout more attractive than defaulting or borrowing from households, which is reflected by a bailout probability and mean bond prices that monotonically increase with $\kappa$. Given that the bailout loan is offered at a favorable price, it allows to roll-over a larger amount of debt for higher values of $\kappa$. This however implies that in the long-run the level of public debt also increases when fiscal constraints are less restrictive. Since increased mean debt levels tend to raise the government's default incentives, the default probability can be a non-monotonic function of $\kappa$. Specifically, for $\widetilde{\beta}=0.9$ (solid) and $\widetilde{\beta}=0.84$ (dashed-dotted) the default probability first declines and then rises when mean debt strongly increases.

A comparison for different degrees of myopia shows that bailout loans exert larger effects 
for higher degrees of myopia, where the tendency to overborrow is more pronounced. The level of mean debt, the default probability, and the mean spread (i.e. the difference between the interest rate $R_{t}$ demanded by households and the risk-free rate $\left.1 / \beta\right)$ increase with the government's impatience and its willingness to borrow. The mean price of public debt is lower for higher degrees of myopia, while the bailout loans then have a larger relative impact on the mean bond price. Evidently, bailout loans can only affect equilibrium outcomes when they are voluntarily accepted by the (myopic) government. The effect of bailout loans on household welfare is therefore relatively small, but can nevertheless be positive (even for $\widetilde{\beta}=0.96$ ) for intermediate values for $\kappa$, like for $\kappa=0.6$. In particular, the maximum welfare gain of bailout loans for $\widetilde{\beta}=0.9$ amounts to less than $2 \%$ of the welfare loss relative to an optimal policy under commitment (see Section 4.2). Notably, the effect of a reduced tightness of the fiscal constraint on welfare is non-monotonic. For values of $\kappa$ that exceed 0.7 , the default probability can increase up to values that are larger than for the case without bailout loans. Correspondingly, welfare falls below the latter case when loans are offered at loose fiscal constraints, e.g. for $\kappa=0.75$. Access to bailout loans then leads to an increase in mean debt, such that the impact on the default probability is reversed. Hence, the enhanced ability to roll-over debt under bailout loans can aggravate the inefficiency induced by overborrowing if bailouts are too generous.

\section{Conclusion}

In this paper, we assess the rationale for conditional bailout loans that are offered to an indebted government, which is not committed to fully repay debt. We consider a government acting under discretion in a closed economy framework, where it faces a trade-off between defaulting on debt held by domestic households, which allows to avoid welfare-reducing tax increases or spending cuts, and avoiding resource costs of default. The government tends to overborrow due to myopia, which leads to non-negligible default probabilities and provides a justification to constrain sovereign borrowing. In this environment, we examine the effectiveness of bailout loans that are offered conditional upon fiscal consolidation, a type of which being offered by the European Stability Mechanism of the European Union.

In particular, we specify loans that are offered by a fund at a risk-free interest rate and conditional upon minimum primary surpluses. In contrast to the government, the fund is assumed to be able to raise revenues in a lump-sum way and to commit to a pre-specified policy, while it can neither enforce debt repayment. We find that the government is willing to accept conditional loans only in states of the economy which lie at the boundary of repayment 
and default states, indicating that conditional loans actually serve as bailouts for governments in adverse states. Specifically, the government tends to favor defaulting in adverse states (high debt and low productivity) and repaying debt in favorable states, while its willingness to accept conditional loans decreases with the tightness of the fiscal constraint. When bailout loans are accepted with a positive probability, the level of public debt increases in the longrun. Nonetheless, the bailout fund, which is endowed with superior technologies (lump-sum financing and commitment) compared to the government, can increase welfare if the imposed fiscal constraint is loose enough to be acceptable, but also sufficiently tight. Otherwise, the enhanced possibility to accumulate debt can even lead to higher default probabilities and higher welfare losses than if no bailout loans were offered. 


\section{References}

Adam, K., and Grill, M., 2012, Optimal Sovereign Debt Default, unpublished manuscript, University of Mannheim.

Ardagna S., and F. Caselli, 2012, The Political Economy of the Greek Debt Crisis: A Tale of Two Bailouts, LSE Center for Economic Performance, Special Paper No.25.

Arellano, C., 2008, Default Risk and Income Fluctuations in Emerging Economies, American Economic Review 98, 690-712.

Aguiar, M. and G. Gopinath, 2006, Defaultable Debt, Interest Rates and the Current Account, Journal of International Economics 69, 64-83.

Aiyagari, S.R., R., Marcet, T.J. Sargent, and J. Seppälä, 2002, Optimal Taxation without State-Contingent Debt, Journal of Political Economy 110, 1220-1254.

Boz, E., 2011, Sovereign Default, Private Sector Creditors, and the IFIs, Journal of International Economics 83, 70-82.

Cole, H. L. and T.J. Kehoe, 2000, Self-fullling Debt Crises, Review of Economic Studies 67, 91-116.

Cuadra, G., J., Sanchez, and H., Sapriza, 2010, Fiscal Policy and Default Risk in Emerging Markets, Review of Economic Dynamics 13, 452-469.

D'Erasmo, P. and E.G. Mendoza (2013), Distributional Incentives in an Equilibrium Model of Domestic Sovereign Default, NBER Working Paper No. 19477.

Derbortoli D. and R. Nunes, 2013, Lack of Commitment and the Level of Debt, Journal of the European Economic Association 11, 1053-1078.

Eaton, J. and M. Gersovitz, 1981, Debt with Potential Repudiation: Theoretical and Empirical Analysis, Review of Economic Studies 48, 289-309.

Grossman, H., and J.B. van Huyck, 1988, Sovereign Debt as a Contingent Claim: Excusable Default, Repudiation, and Reputation, American Economic Review 78, 1088-1097.

Hatchondo, J.C., L. Martinez, H. Sapriza, 2010, Quantitative properties of sovereign default models: Solution methods matter, Review of Economic Dynamics 13, 919-933.

Klein, P., Krusell, P. and J.-V. Ríos-Rull, 2008, Time-Consistent Public Policy, Review of Economic Studies 75, 789-808.

Krusell, P., Fernando M., and J.-V. Ríos-Rull, 2006, Time-Consistent Debt, unpublished manuscript, Institute for International Economic Studies.

Lucas, R.E. and N.L. Stokey, 1983, Optimal Fiscal and Monetary Policy in an Economy without Capital, Journal of Monetary Economics 12, 55-93.

Panizza, U., Sturzenegger, F. and J. Zettelmeyer, 2009, The Economics and Law of Sovereign 
Debt and Default, Journal of Economic Literature 47, 651-698.

Pouzo, D., 2013, Optimal Taxation with Endogenous Default under Incomplete Markets, unpublished manuscript, UC Berkeley.

Reinhart, C.M. and K.S. Rogoff, 2011, The Forgotten History of Domestic Debt, Economic Journal 121, 319-350.

Roch, F., and H. Uhlig, 2012, The Dynamics of Sovereign Debt Crises and Bailouts, unpublished manuscript, University of Chicago.

Tauchen, G., 1986, Finite State Markov Chain Approximations to Univariate and Vector Autoregressions, Economics Letter 20, 177-181.

Tomz, M. and M.L.J. Wright, 2007, Do Countries Default in Bad Times?, Journal of the European Economic Association 5, 352-360. 


\section{A Appendix to Section 3}

Proof of proposition 1. We first examine the problem of a government which aims at maximizing household welfare under commitment, including full debt repayment $p_{t}=$ $1 \forall t \geq 0$. Given that public debt is non-state-contingent, there does not exist a single implementability constraint (see Aiyagari et al., 2002). The problem of a government can then be summarized by considering the equilibrium conditions as constraints and a set of implementability constraints for all periods $t$, or equivalently as

$$
\begin{array}{rl}
\max _{l_{t}, g_{t}, \tau_{t}, b_{t}} & E \sum_{t=0}^{\infty} \beta^{t} u\left(\Xi_{t} f\left(l_{t}\right)-g_{t}, l_{t}, g_{t}\right) \quad \text { s.t. } \\
& 0=u_{l, t} /\left[u_{c, t}\left(\Xi_{t} f\left(l_{t}\right)-g_{t}\right)\right]+\left(1-\tau_{t}\right) \Xi_{t} f^{\prime}\left(l_{t}\right), \\
& 0=\tau_{t} \Xi_{t} f^{\prime}\left(l_{t}\right) l_{t}-g_{t}+\beta E_{t} \frac{u_{c, t+1}\left(\Xi_{t+1} f\left(l_{t+1}\right)-g_{t+1}\right)}{u_{c, t}\left(\Xi_{t} f\left(l_{t}\right)-g_{t}\right)} b_{t}-b_{t-1},
\end{array}
$$

and the transversality condition, where $\Xi_{t}=\Xi\left(a_{t}, 1\right)$. The first order conditions for the tax rate, government spending, working time, and debt are given by

$$
\begin{aligned}
0= & \mu_{t} \Xi_{t} f^{\prime}\left(l_{t}\right)-\gamma_{t} \Xi_{t} f^{\prime}\left(l_{t}\right) l_{t}, \forall t \geq 0, \\
0= & -u_{c, t}+u_{g, t}+\mu_{t} u_{c c, t}\left(u_{l, t} / u_{c, t}^{2}\right)-\gamma_{t}+\gamma_{t} u_{c c, t} \beta E_{t} \frac{u_{c, t+1}}{u_{c, t}^{2}} b_{t}-\gamma_{t-1} \frac{u_{c c, t}}{u_{c, t-1}} b_{t-1}, \forall t \geq 1, \\
0= & -u_{c, 0}+u_{g, 0}+\mu_{t} u_{c c, 0}\left(u_{l, 0} / u_{c, 0}^{2}\right)-\gamma_{0}+\gamma_{0} u_{c c, 0} \beta E_{0} \frac{u_{c, 0+1}}{u_{c, 0}^{2}} b_{0}, \\
0= & u_{c, t} \Xi_{t} f_{t}^{\prime}+u_{l, t}+\mu_{t}\left(u_{l l, t} / u_{c, t}\right)-\mu_{t} u_{c c, t} \Xi_{t} f_{t}^{\prime}\left(u_{l, t} / u_{c, t}^{2}\right)+\mu_{t}\left(1-\tau_{t}\right) \Xi_{t} f^{\prime \prime}\left(l_{t}\right), \\
& +\gamma_{t} \tau_{t} \Xi_{t}\left(f^{\prime}\left(l_{t}\right)+f^{\prime \prime}\left(l_{t}\right) l_{t}\right)-\gamma_{t} u_{c c, t} \beta E_{t} \Xi_{t} f_{t}^{\prime} \frac{u_{c, t+1}}{u_{c, t}^{2} m} b_{t}+\gamma_{t-1} \Xi_{t} f_{t}^{\prime} \frac{u_{c c, t}}{u_{c, t-1}} b_{t-1}, \forall t \geq 1, \\
0= & u_{c, 0} \Xi_{0} f_{0}^{\prime}+u_{l, 0}+\mu_{0}\left(u_{l l, 0} / u_{c, 0}\right)-\mu_{0} u_{c c, 0} \Xi_{0} f_{0}^{\prime}\left(u_{l, 0} / u_{c, 0}^{2}\right)+\mu_{0}\left(1-\tau_{0}\right) \Xi_{0} f^{\prime \prime}\left(l_{0}\right) \\
& +\gamma_{0} \tau_{0} \Xi_{0}\left(f^{\prime}\left(l_{0}\right)+f^{\prime \prime}\left(l_{0}\right) l_{0}\right)-\gamma_{0} u_{c c, 0} \beta E_{0} \Xi_{0} f_{0}^{\prime} \frac{u_{c, 0+1}}{u_{c, 0}^{2} m} b_{0}, \\
0= & \gamma_{t} q_{t}-\beta E_{t} \gamma_{t+1}, \forall t \geq 0,
\end{aligned}
$$

where $\mu_{t}$ and $\gamma_{t}$ denote the multiplier on (28) and (29). An equilibrium allocation for an optimizing government acting under commitment is a thus set of sequences $\left\{\mu_{t}, \gamma_{t}, g_{t}, l_{t}\right.$, $\left.\tau_{t}, c_{t}, b_{t}\right\}_{t=0}^{\infty}$ satisfying (28)-(35), $\Xi_{t} f\left(l_{t}\right)=c_{t}+g_{t}, \lim _{t \rightarrow \infty} E\left(b_{t} / R_{t}\right) \prod_{i=1}^{t}\left(1 / R_{i-1}\right)=0$, given $b_{-1}>0$. The optimal policy under commitment is time inconsistent if households are risk averse, $u_{c c}<0$, which can immediately be seen from a comparison of (31) and (32) as well as of (33) and (34). If $u_{c c}=0$, the price for government bonds $q_{t}$ equals $\beta$ (see 4). Then, (29) simplifies to

$$
\tau_{t} \Xi_{t} f^{\prime}\left(l_{t}\right) l_{t}-g_{t}+\beta b_{t}=b_{t-1}
$$


such that there is no forward-looking equilibrium condition that serves as a relevant constraint for the government problem (see 27)-(29). Then, (31), (32), (33), and (34) reduce to the following two conditions that apply for all periods $t \geq 0$ :

$$
\begin{aligned}
\gamma_{t} & =u_{g, t}-u_{c, t}, \\
-u_{l, t} & =u_{c, t} \Xi_{t} f_{t}^{\prime}+\mu_{t}\left(u_{l l, t} / u_{c, t}\right)+\mu_{t}\left(1-\tau_{t}\right) \Xi_{t} f^{\prime \prime}\left(l_{t}\right)+\gamma_{t} \tau_{t} \Xi_{t}\left(f^{\prime}\left(l_{t}\right)+f^{\prime \prime}\left(l_{t}\right) l_{t}\right),
\end{aligned}
$$

where $\Xi_{t}=\Xi\left(a_{t}, 1\right)$, implying that the policy plan is time consistent.

Now consider the government's problem without commitment. If default costs are prohibitively high, $\Xi\left(a_{t}, 1\right) \rightarrow 0$, private and public consumption satisfy $c_{t} \rightarrow 0$ and $g_{t} \rightarrow 0$ under the default choice, implying $u\left(c_{t}, g_{t}, l_{t}\right) \rightarrow-\infty$ by $(24)$ and $V^{d}\left(b_{t-1}, a_{t}\right) \rightarrow-\infty$ by (19), such that the default set is empty, $\Lambda\left(b_{t-1}\right)=\varnothing$. The choice of a government that lacks commitment is then characterized by (21)-(23) and $\gamma_{t}\left[q_{t}+\beta E_{t}\left(\frac{u_{c c, t+1}}{u_{c, t}} \frac{\partial c_{t+1}}{\partial b_{t}}\right) b_{t}\right]=\widetilde{\beta} E_{t} \gamma_{t+1}$ as well as (28) and (29). When the government is non-myopic $\widetilde{\beta}=\beta$ and households are risk-neutral, $u_{c c, t}=0$, these conditions reduce to (28), (30), (36), (37), (38) and $u_{g, t}-u_{c, t}=E_{t}\left(u_{g, t+1}-u_{c, t+1}\right)$, which are evidently identical to the conditions describing fiscal policy under commitment for $u_{c c, t}=0$ (see above). This establishes the claims made in the proposition.

\section{B Appendix to Section 4}

Under risk-neutrality, $u_{c c}=0$, the government's optimality conditions for the tax rate, expenditures and working time under full repayment (21)-(23) exhibit the same form as the conditions under the default choice, $p_{t}=0$, which are given by

$$
\begin{aligned}
& 0=\mu_{t} \Xi_{t} f^{\prime}\left(l_{t}\right)-\gamma_{t} \Xi_{t} f^{\prime}\left(l_{t}\right) l_{t}, \\
& 0=u_{g, t}-u_{c, t}-\gamma_{t}, \\
& 0=u_{c, t} \Xi_{t} f_{t}^{\prime}+u_{l, t}+\mu_{t}\left(u_{l l, t} / u_{c, t}\right)+\mu_{t}\left(1-\tau_{t}\right) \Xi_{t} f^{\prime \prime}\left(l_{t}\right)+\gamma_{t} \tau_{t} \Xi_{t}\left(f^{\prime}\left(l_{t}\right)+f^{\prime \prime}\left(l_{t}\right) l_{t}\right),
\end{aligned}
$$

while $\Xi_{t}$ now $\Xi_{t}=\Xi\left(a_{t}, 0\right)$ under default and $\mu_{t}$ and $\gamma_{t}$ denote the multipliers for (28) and $\tau_{t} \Xi_{t} f^{\prime}\left(l_{t}\right) l_{t}=g_{t}$. Further using $-u_{l, t} / u_{c, t}=\left(1-\tau_{t}\right) \Xi_{t} f^{\prime}\left(l_{t}\right)$ and (39)-(40) to eliminate $\Xi_{t}$ and the multipliers $\gamma_{t}$ and $\mu_{t}$, shows that the government's optimal instrument choice is characterized by

$$
u_{c, t}\left(\frac{u_{l l, t} l_{t}}{u_{l, t}}\left(1-\tau_{t}\right)-\frac{f^{\prime \prime}\left(l_{t}\right) l_{t}}{f^{\prime}\left(l_{t}\right)}\right)=u_{g, t}\left(\frac{u_{l l, t} l_{t}}{u_{l, t}}\left(1-\tau_{t}\right)-\frac{f^{\prime \prime}\left(l_{t}\right) l_{t}}{f^{\prime}\left(l_{t}\right)}-\tau_{t}\right)
$$

Under full repayment, the government's choice is further constrained by $\tau_{t} \Xi_{t} f^{\prime}\left(l_{t}\right) l_{t}-g_{t}+$ $\beta E_{t} \frac{\left[\left(1-\delta_{t+1}\right) u_{c, t+1}\left(\Xi_{t+1} f\left(l_{t+1}\right)-g_{t+1}\right)\right]}{u_{c, t}\left(\Xi_{t} f\left(l_{t}\right)-g_{t}\right)} b_{t}=b_{t-1}$, which reduces to $\tau_{t} \Xi_{t} f^{\prime}\left(l_{t}\right) l_{t}-g_{t}+q_{t} b_{t}=b_{t-1}$. 
Let $a=a_{t}, a^{\prime}=a_{t+1}, b=b_{t-1}, b^{\prime}=b_{t}, q=q_{t}, g=g_{t}, \tau=\tau_{t}$, and $l=l_{t}$. Then, we can summarize the Markov perfect equilibrium under a government acting without commitment in terms of working time, government spending, the tax rate, the bond price, consumption, and end-of-period debt as time invariant functions of the state variables $a$ and $b, l(a, b)$, $g(a, b), \tau(a, b), q\left(a, b^{\prime}\right), c(a, b)$, and $b^{\prime}(a, b)$, satisfying (13),

$$
q\left(a, b^{\prime}\right)=\beta\left[1-\sum_{a^{\prime} \in \Lambda\left(b^{\prime}(a, b)\right)} \pi\left(a^{\prime} \mid a\right)\right],
$$

(15), (17), (42), and a choice for $b^{\prime}$ that satisfies (18) if $a \in \Theta(b), b^{\prime}=\kappa b$ if $a \in \digamma(b)$, or $b=0$ if $a \in \Lambda(b)$. For the functional forms for the utility function and the deterministic part of the production function introduced in (24) and (26), condition (42) can the be simplified to

$$
\frac{g(a, b)^{-\sigma}}{\psi}=\frac{1-\alpha+\eta(1-\tau(a, b))}{1-\alpha+\eta(1-\tau(a, b))-\tau(a, b)}
$$

while (13), (15), and (17) are given by

$$
\begin{aligned}
& l(a, b)=[(\alpha \psi / \vartheta)(1-\tau(a, b)) \Xi(a, p)]^{1 /(\eta+1-\alpha)}, \\
& g(a, b)=\tau(a, b) \Xi(a, p) \alpha l(a, b)^{\alpha}+p\left[q(b, a) b^{\prime}(a, b)-b\right], \\
& c(a, b)=\Xi(a, p) l(a, b)^{\alpha}-g(a, b),
\end{aligned}
$$

where $p \in\{0,1\}$.

\section{Numerical Solution}

The model is solved using off-grid value function iteration. Apart from the default and bailout choice, all policies are continuous. Value and policy functions are approximated on equidistant grids with 25 points for productivity and 31 points for debt, allowing for off-grid choices using cubic spline interpolation for policy and value functions (following Hatchondo et al., 2010). As a robustness check (and to generate initial guesses), we also solved the model using discrete state space value function iteration using a very large number of grid points for debt and productivity. In the off-grid algorithm, we calculate expectations with respect to productivity using a very fine grid for productivity (2501 points) and the respective transition probabilities generated using the Tauchen (1986) algorithm. Throughout, we set the width of the productivity grid to \pm 3.25 standard deviations. The value function iteration is stopped when the maximum absolute difference between value and policy functions in two consecutive iterations is below $10^{-6}$. To speed up the simulation of the model, we interpolated the policy functions on a large grid and used on-grid simulation. 
We performed a number of checks to make sure that our numerical solution is sufficiently precise. For instance, in the stochastic simulations, we compared the actual optimal choice of government spending from our numerical solution to the level of government spending that is implied ex-post by the government budget constraint (by substituting the components of the budget constraint through the simulated series for the tax rate, debt, and the bond price). The maximum difference between these two series for government spending is $1.51 \mathrm{e}^{-05}$, with a standard deviation of $8.04 \mathrm{e}^{-06}$. We also checked that solving the model on a finer grid and using more time periods and repetitions for the simulation has close to no influence on the results.

\section{Conditional loans in a simplified model}

Consider a two-period deterministic $\left(a=a^{\prime}=1\right)$ version of the model for $b>0$. Household welfare is then given by $u(c, g, l)+\beta u\left(c^{\prime}, g^{\prime}, l^{\prime}\right)$. Suppose that the government accepts the loan conditional upon the fiscal constraint (7), which is assumed to be binding. Its choice then satisfies (43), (44), and (46), as well as

$$
s=\frac{1}{1+\beta / \Psi} b \text { and } s^{\prime}=\frac{1}{\Psi+\beta} b,
$$

where $s=\tau f(l)-g$ and $s^{\prime}=\tau^{\prime} f\left(l^{\prime}\right)-g^{\prime}$. For the simplifying parameter values $\alpha=\sigma=\eta=1$, these conditions immediately lead to the time invariant functions $\tau(g)=\psi(1-\psi g) / \Gamma(g)$ and $l(g)=\psi /[\vartheta \Gamma(g)]$, where $\Gamma(g)=1+\psi(1-g \psi)$. Hence, the primary surplus satisfies

$$
s(g)=\psi^{2} \frac{1-\psi g}{\vartheta \Gamma(g)^{2}}-g .
$$

Given that (47) and (48) imply $g<1 / \psi$ and thus $\Gamma(g)>0$, the primary surplus is strictly decreasing in $g: \partial s(g) / \partial g=-\frac{\psi^{3}}{\vartheta \Gamma(g)^{2}}-2 \frac{\psi^{4}}{\vartheta} \frac{g \psi-1}{\Gamma(g)^{3}}-1<0$. Household utility can further be simplified to $u(g)=-g \psi+\log g+\left[\psi^{2} /(2 \vartheta)\right][2 \psi(1-g \psi)+1] / \Gamma(g)^{2}$, implying that $\partial u(g) / \partial g=$ $-\psi+g^{-1}+\left(\psi^{5} / \vartheta\right)(1-g \psi) / \Gamma(g)^{3}>0$. Thus, the two conditions in (47) imply that an increase in the parameter $\Psi$, which governs the tightness of the fiscal constraint (7), leads to a lower level of government expenditures $g$ and thereby to a lower utility $u$, while it raises $g^{\prime}$ and $u^{\prime}$. 


\section{E Additional figures}
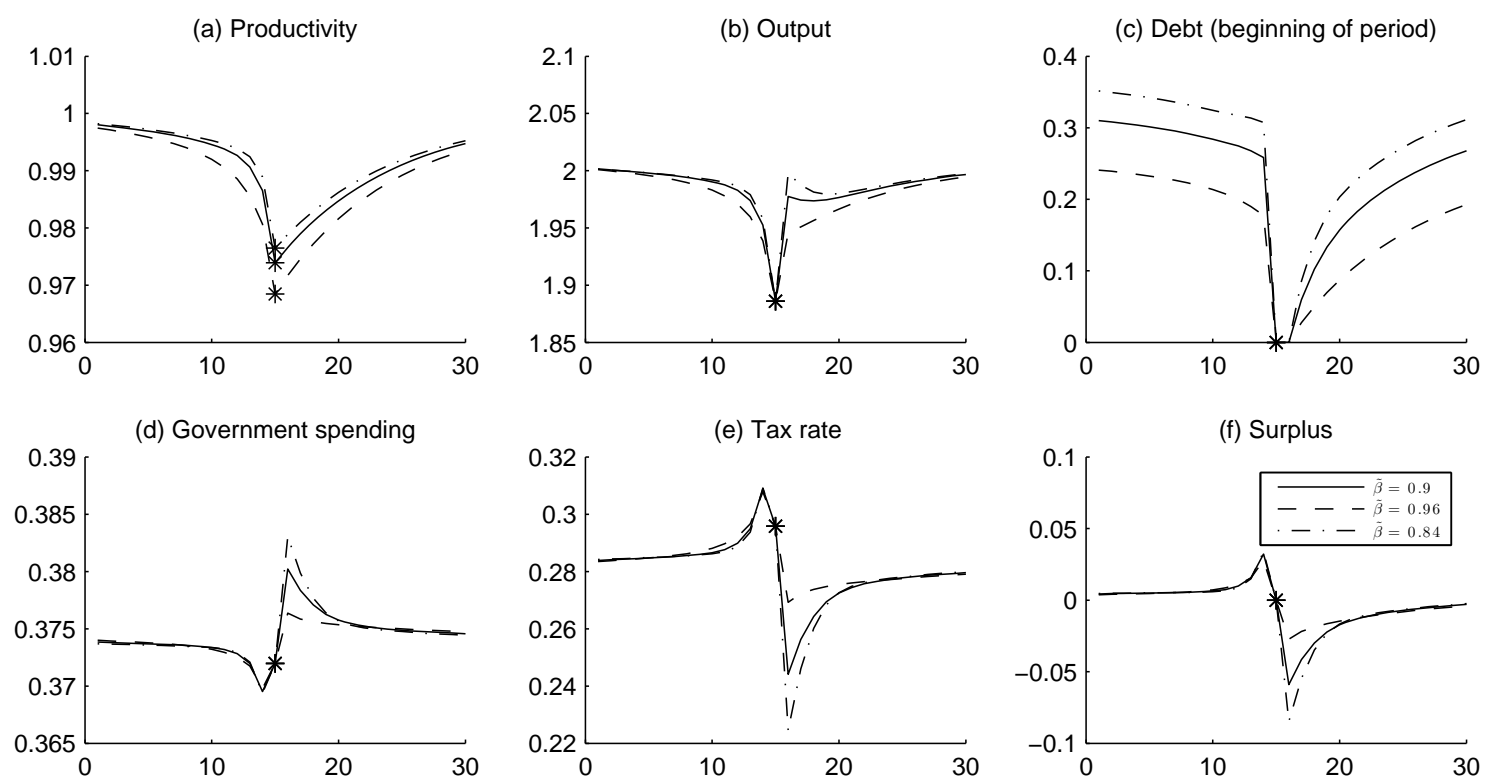

Figure 6: Means of selected variables conditional upon their realizations prior to a default period ( $t=15$, marked with a star) for different degrees of myopia
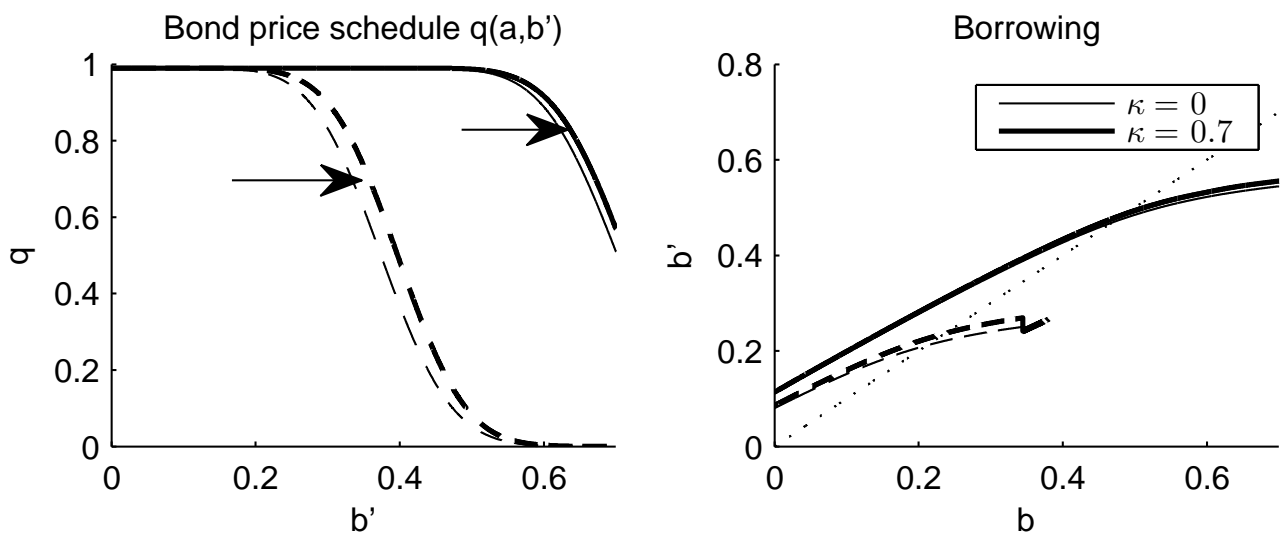

Figure 7: Bond prices and government borrowing with bailouts, $\kappa=0.7$, (bold lines) and w/o bailouts, $\kappa=0$, for high (solid lines) and low (dashed lines) productivity 

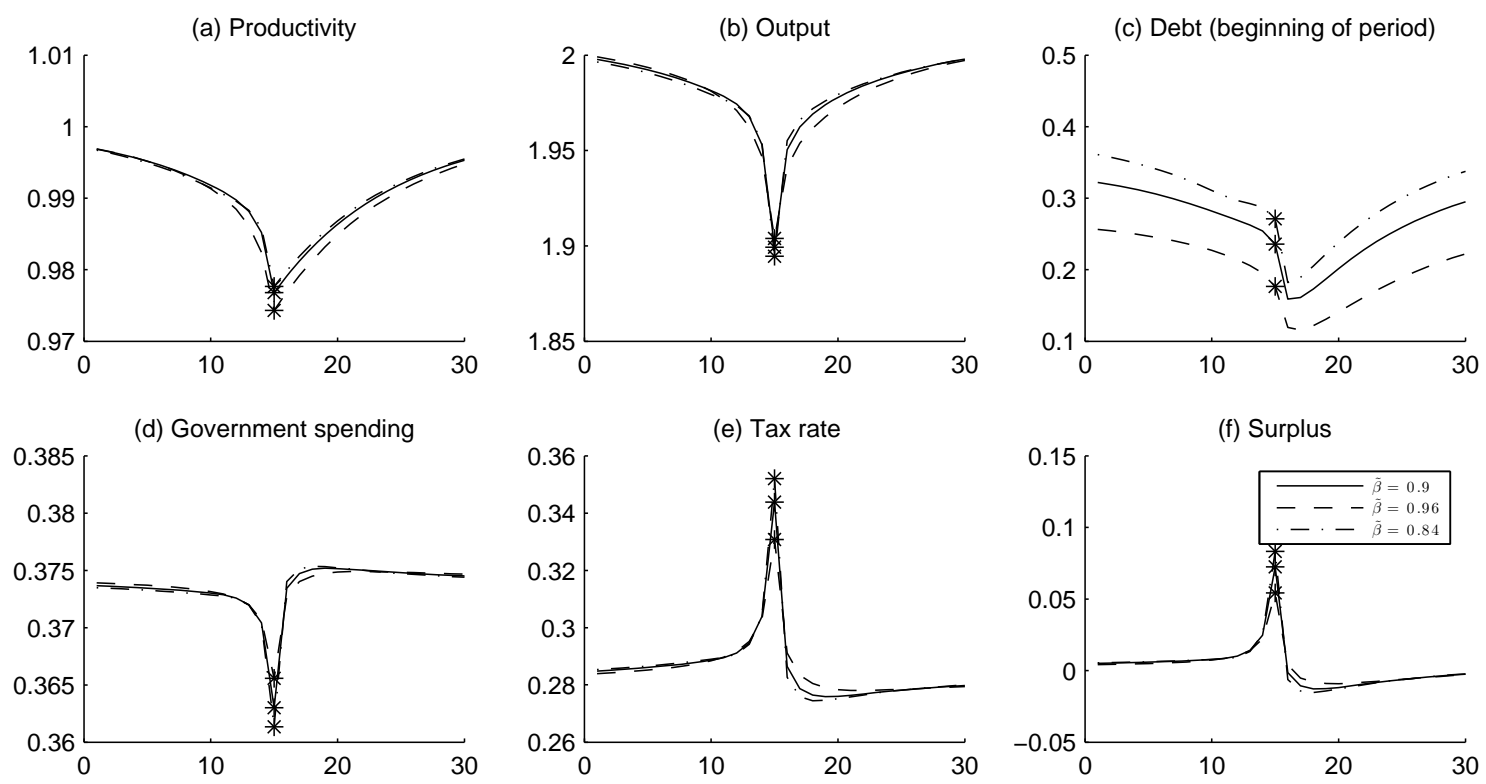

Figure 8: Means of selected variables conditional upon their realizations prior to a bailout period $(t=15$, marked with a star) for different degrees of myopia 